\title{
Accuracy Testing of Steel and Electric Groundwater-Level Measuring Tapes: Test Method and In-Service Tape Accuracy \\ d
}
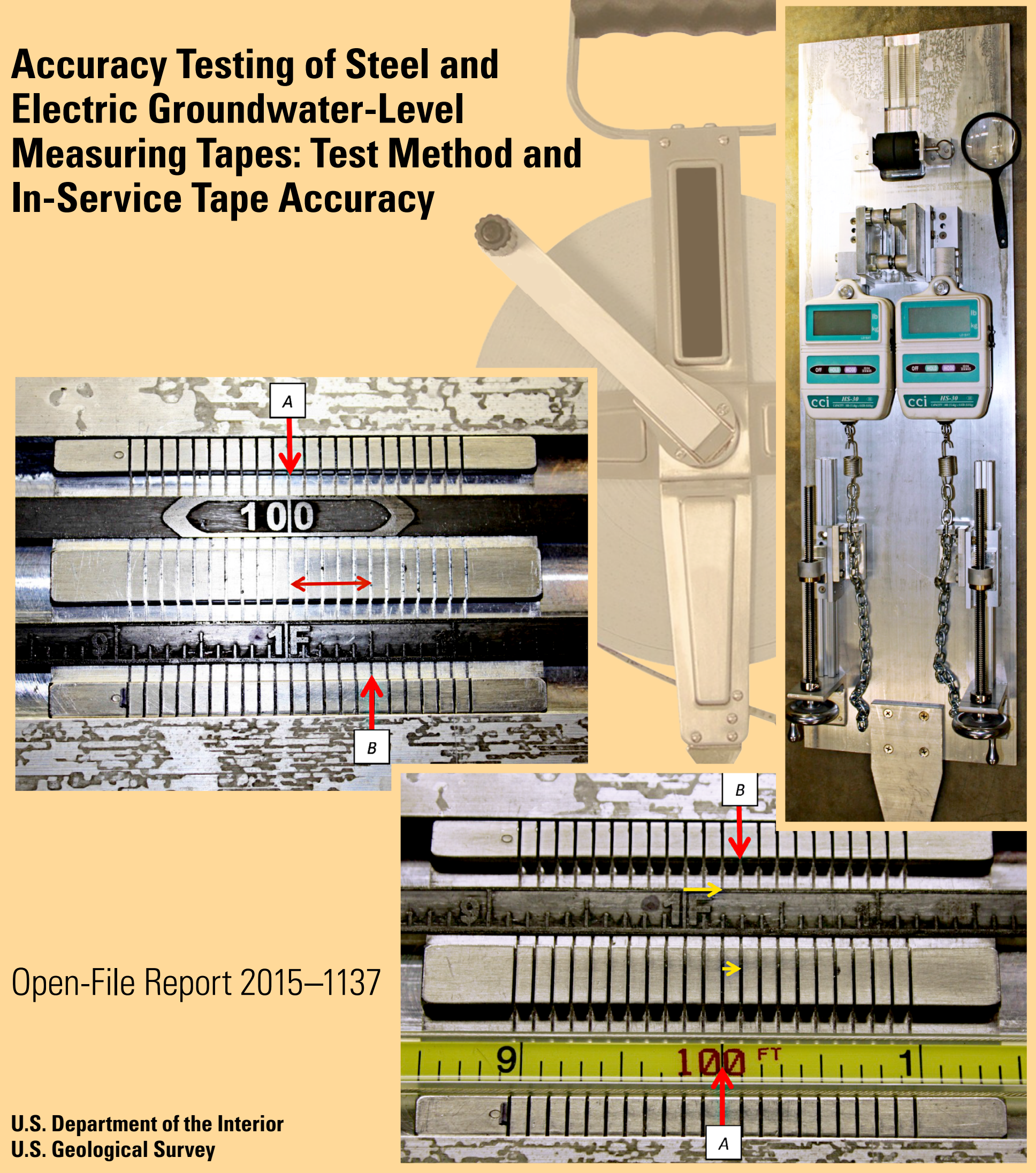

U.S. Department of the Interior U.S. Geological Survey

Open-File Report 2015-1137 


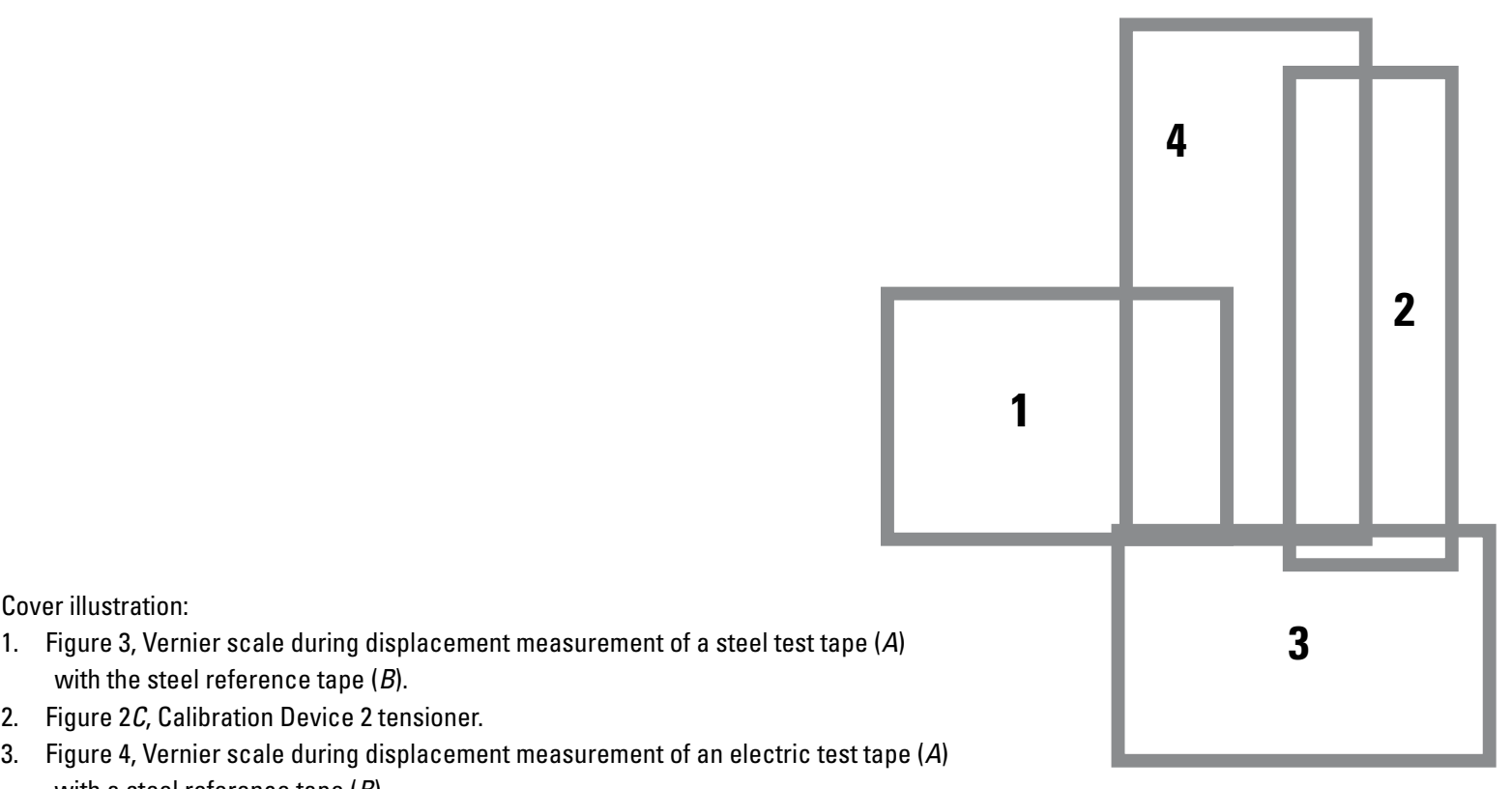

3. Figure 4 , Vernier scale during displacement measurement of an electric test tape $(A)$ with a steel reference tape $(B)$.

4. Steel tape on reel. 


\section{Accuracy Testing of Steel and Electric Groundwater-Level Measuring Tapes: Test Method and In-Service Tape Accuracy}

By Janice M. Fulford and Christopher S. Clayton

Open-File Report 2015-1137 


\title{
U.S. Department of the Interior SALLY JEWELL, Secretary
}

\section{U.S. Geological Survey \\ Suzette M. Kimball, Acting Director}

\author{
U.S. Geological Survey, Reston, Virginia: 2015
}

For more information on the USGS - the Federal source for science about the Earth, its natural and living resources, natural hazards, and the environment—visit http://www.usgs.gov or call 1-888-ASK-USGS.

For an overview of USGS information products, including maps, imagery, and publications, visit http://www.usgs.gov/pubprod/.

Any use of trade, firm, or product names is for descriptive purposes only and does not imply endorsement by the U.S. Government.

Although this information product, for the most part, is in the public domain, it also may contain copyrighted materials as noted in the text. Permission to reproduce copyrighted items must be secured from the copyright owner.

Suggested citation:

Fulford, J.M., and Clayton, C.S., 2015, Accuracy testing of steel and electric groundwater-level measuring tapes-Test method and in-service tape accuracy: U.S. Geological Survey Open-File Report 2015-1137, 31 p., http://dx.doi.org/10.3133/ofr20151137.

ISSN 2331-1258 (online) 


\section{Contents}

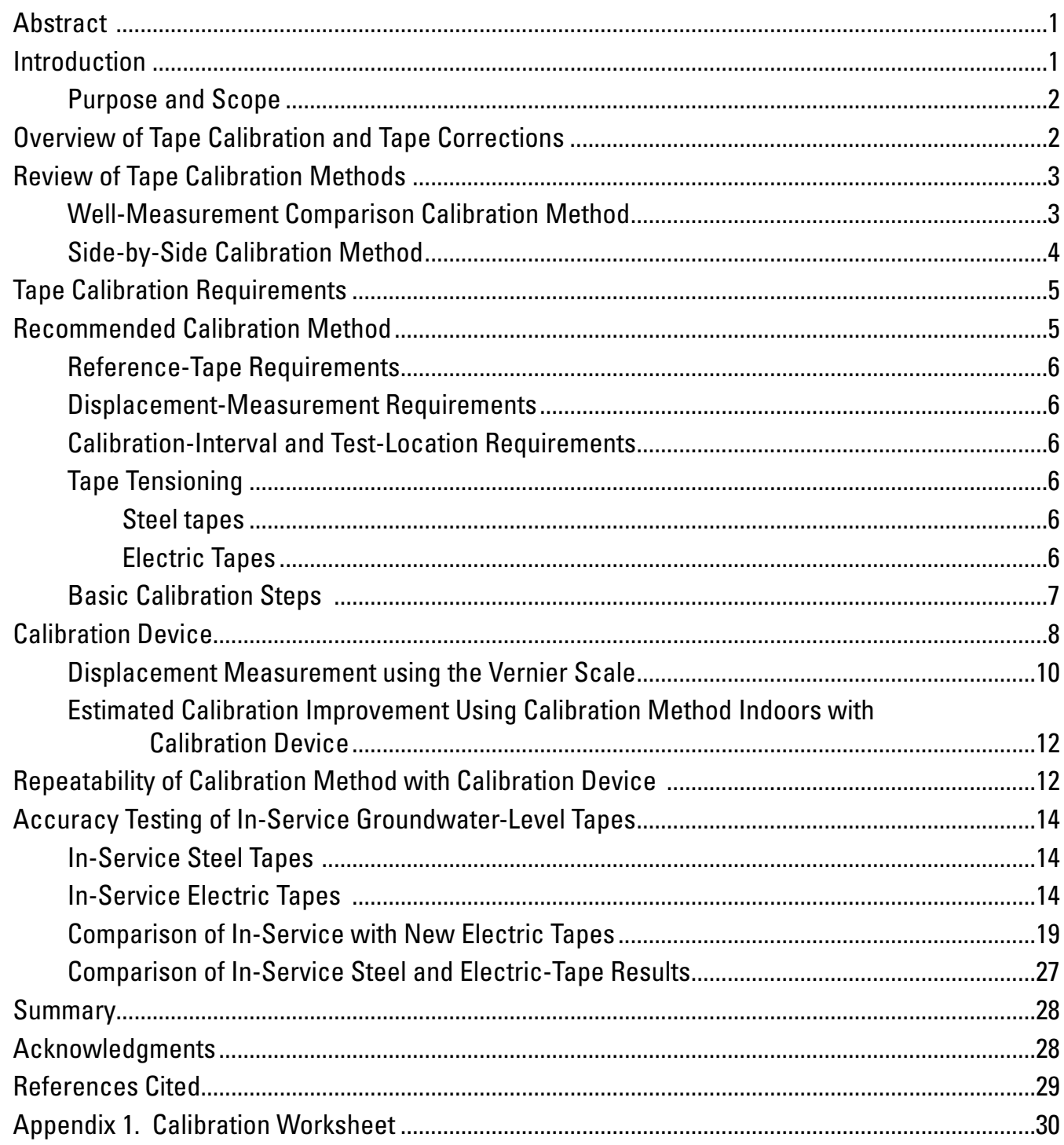

\section{Figures}

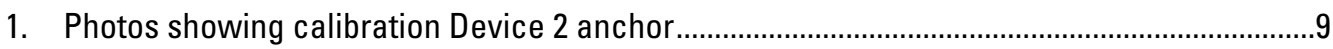

2. Photos showing calibration Device 2 tensioner ......................................................................

3. Photo showing close-up view of Vernier scale during displacement measurement of a steel test tape with a steel reference tape.............................................................11

4. Photo showing close-up view of Vernier scale during displacement measurement of an electric test tape with a steel reference tape

5. Graph showing the cumulative measured displacement between 15 USGS in-service steel test tapes and the steel reference tape with an expected accuracy of 0.01 foot per 100 -foot length. 
6. Graph showing the cumulative measured displacement for 100 -foot graduation intervals between in-service steel test tapes less than 300 feet in length and the steel reference tape.

7. Graph showing the cumulative measured displacement for 100 -foot graduation intervals between in-service 300 -foot steel test tapes and the steel reference tape.

8. Graph showing the cumulative measured displacement for 100 -foot graduation intervals between in-service steel test tapes greater than 300 feet in length and the steel reference tape ...

9. Charts showing new and 14 USGS Water Science Center in-service electric test tapes, the cumulative measured displacement between electric test tapes and the steel reference tape with an expected accuracy of 0.01 foot per 100 -ft length.

10. Charts showing the cumulative measured displacement between Solinst model 101 electric test tapes and the steel reference tape with an expected accuracy of 0.01 foot per 100-ft length for new and for USGS Water Science Center in-service electric test tapes.

11. Charts showing the cumulative measured displacement between Slope Indicator electric test tapes and the steel reference tape with an expected accuracy of 0.01 foot per 100-ft length for new and for USGS Water Science Center in-service electric test tapes.

12. Charts showing the cumulative measured displacement between Keck electric test tapes and the steel reference tape with an expected accuracy of 0.01 foot per 100-ft length for new and for USGS Water Science Center in-service electric test tapes.

13. Charts showing the cumulative measured displacement between Heron electric test tapes and the steel reference tape with an expected accuracy of 0.01 foot per 100-ft length for new and for USGS Water Science Center in-service electric test tapes

14. Chart showing the cumulative measured displacement between in-service Solinst model 102 electric test tapes and the steel reference tape with an expected accuracy of 0.01 foot per 100 -ft length.

15. Chart showing the cumulative measured displacement between in-service RST model 3001 electric test tapes and the steel reference tape with an expected accuracy of 0.01 foot per $100-f t$ length

16. Chart showing for new and in-service electric test tapes with steel tape cores, the cumulative measured displacement between electric test tapes and the steel reference tape with an expected accuracy of 0.01 foot per $100-\mathrm{ft}$ length.

17. Chart showing for new and in-service electric test tapes without steel tape cores, the cumulative measured displacement between electric test tapes and the steel reference tape with an expected accuracy of 0.01 foot per 100-ft length

18. Chart showing for steel and in-service electric test tapes, the cumulative measured displacement between in-service test tapes and the steel reference tape with an expected accuracy of 0.01 foot per $100-\mathrm{ft}$ length

\section{Tables}

1. Example of tape marking correction table for a fictional electric tape

2. Electric groundwater-level measuring-tape probe and tape weights for various models and calibration tensions by tape interval used to simulate in-use tensions 
3. Summary statistics of measured displacement between test tape and reference tape over 100-foot intervals for all individual interval measurements..

4. Summary statistics of 10 replicated steel tape calibrations using four repeated measurements to determine the average displacement with reference tape in feet over 100-foot intervals.

5. Summary statistics of 20 replicated steel tape calibrations using two repeated measurements to determine the average displacement with reference tape in feet over $100-\mathrm{ft}$ intervals.

6. Effect of sample size on interval-displacement measurement accuracy using a measurement standard deviation of 0.0011 foot.

7. Information for in-service steel tapes manufactured by Lufkin and calibrated by proposed procedure and device

8. Summary statistics of measured displacement between in-service steel tape and reference tape over 100-foot intervals for all individual interval measurements

9. Summary statistics for 15 in-service steel tapes, using four repeated measurements to determine the displacement with the reference tape over a $100-\mathrm{ft}$ interval

10. Based on the USGS Office of Groundwater survey, comparison of quantity and makes of in-service electric groundwater-level tapes with the study numbers and makes of in-service electric tapes

11. Information for the sample of in-service electric tapes used to check accuracy of electric groundwater-level tapes used by the USGS

12. Summary statistics of in-service electric-tape measurements, individual interval-displacement measurements, and probe-offset errors .

13. Summary statistics of in-service electric groundwater-level tape displacement measurements using four measurements for each 100-foot interval..

14. Summary statistics of in-service electric groundwater-level tape displacement measurements over 100-ft tape intervals by model.

15. New and in-service electric-tape calibration data. Displacement is the measured length difference between the electric tape and the steel reference tape

\section{Conversion Factors}

\begin{tabular}{lcl} 
Inch/Pound to SI & & \\
\hline \multicolumn{1}{c}{ Multiply } & By & To obtain \\
\hline & Length & \\
\hline inch (in.) & 25.4 & millimeter $(\mathrm{mm})$ \\
inch (in.) & 0.08333 & foot (ft) \\
foot (ft) & 0.3048 & meter (m) \\
\hline & Mass & \\
\hline pound, avoirdupois (lb) & 0.4536 & kilogram (kg) \\
\hline
\end{tabular}

Temperature in degrees Fahrenheit $\left({ }^{\circ} \mathrm{F}\right)$ may be converted to degrees Celsius $\left({ }^{\circ} \mathrm{C}\right)$ as follows: ${ }^{\circ} \mathrm{C}=\left({ }^{\circ} \mathrm{F}-32\right) / 1.8$

Specific conductance is given in microsiemens per centimeter at 25 degrees

Celsius $\left(\mu \mathrm{S} / \mathrm{cm}\right.$ at $\left.25^{\circ} \mathrm{C}\right)$. 



\title{
Accuracy Testing of Steel and Electric Groundwater-Level Measuring Tapes: Test Method and In-Service Tape Accuracy
}

\author{
by Janice M. Fulford and Christopher S. Clayton
}

\section{Abstract}

The accuracy of groundwater-level tapes was investigated by developing a tape calibration method and device and testing the accuracy of a sample of groundwater-level tapes with the calibration method and device. The sample of tapes included in-service U.S. Geological Survey (USGS) Water Science Center steel and electric groundwater-level tapes.

The tape calibration method developed during the study is based on a National Institute for Standards and Technology (NIST) protocol, and compares the tape under calibration (test tape) with a NIST-traceable reference tape. The calibration method can be used to determine tape accuracy and tape corrections. The tape calibration device consists of an anchor and tensioner. The device allows individual tensioning of the test and reference tapes. The Vernier scale on the tensioner allows measurement of the difference (or displacement) between the test and reference tapes graduations with a resolution of 0.0005 foot (ft). The calibration method used with the calibration device has a repeatability (standard deviation) of $0.0011 \mathrm{ft}$.

The calibration device and proposed method were used to calibrate a sample of in-service USGS steel and electric groundwater tapes. The sample of in-service groundwater steel tapes were in relatively good condition. All steel tapes, except one, were accurate to $\pm 0.01 \mathrm{ft}$ per $100 \mathrm{ft}$ over their entire length. One steel tape, which had obvious damage in the first hundred feet, was marginally outside the accuracy of $\pm 0.01 \mathrm{ft}$ per $100 \mathrm{ft}$ by $0.001 \mathrm{ft}$. The sample of in-service groundwaterlevel electric tapes were in a range of conditions-from like new, with cosmetic damage, to nonfunctional. The in-service electric tapes did not meet the USGS accuracy recommendation of $\pm 0.01 \mathrm{ft}$. In-service electric tapes, except for the nonfunctional tape, were accurate to about $\pm 0.03 \mathrm{ft}$ per $100 \mathrm{ft}$. A comparison of new with in-service electric tapes found that steel-core electric tapes maintained their length and accuracy better than electric tapes without a steel core. The in-service steel tapes could be used as is and achieve USGS accuracy recommendations for groundwater-level measurements. The in-service electric tapes require tape corrections to achieve USGS accuracy recommendations for groundwater-level measurements.

\section{Introduction}

The U.S. Geological Survey (USGS) uses steel and electric measurement tapes to measure groundwater levels and to verify the accuracy of pressure transducers installed in groundwater wells. USGS groundwater-level measurements are used by water managers and scientists to make decisions about water allocations, to calibrate groundwater-flow models, and to assess groundwater flow and supply. The quality of groundwater-level measurements is directly related to the accuracy of the tapes used for those measurements. Because of the importance of groundwater-level measurements, USGS Water Science Centers (WSCs) are required by the USGS Office of Groundwater (OGW) to have a quality-assurance program (Brunett and others, 1997) that includes the calibration of all steel and electric tapes used for groundwater-level measurements. The details and frequency of the procedure used to calibrate WSC tapes is required to be part of the WSC quality assurance plan and is reviewed triennially during technical reviews of the WSC data program.

Techniques and Methods 1-A1, "Groundwater Technical Procedures of the U.S. Geological Survey" (Cunningham and Schalk, 2011a, 2011b), describes the use of steel and electric tapes for USGS groundwater-level measurements. Its purpose is to "provide a citable document for technical field procedures" (p. 2) and guidance for USGS qualityassurance procedures. The report states that "graduated steel tape is commonly accurate to 0.01 foot" (Cunningham and 
Schalk, 2011a, p. 5) and that "modern graduated electric tape is commonly accurate to \pm 0.01 foot" (Cunningham and Schalk, 2011b, p. 33).

Techniques and Methods 1-A1 also gives general information on conducting a groundwater-level tape calibration to verify tape accuracy. The report recommends annual or more frequent calibration of steel and electric tapes when a tape is abnormally stressed or damaged in some way, and a steel tape for the calibration reference. However, the report does not mention whether the calibration reference tape needs traceability to a National Institute of Standards and Technology (NIST) reference. No specific calibration procedure for steel tapes and only vague calibration guidance for electric tapes are given in the Techniques and Methods report. Because no detailed tape calibration guidance is given, each WSC determines the detailed procedure used to calibrate their groundwater-level tapes. The lack of a uniform detailed calibration method may result in some groundwater measurements having a lower quality. Additionally, little information is readily available to verify the measurement performance of USGS in-service groundwater tapes.

The USGS Hydrologic Instrumentation Facility (HIF) was tasked by the OGW to evaluate groundwater tape calibration methods and the accuracy of USGS in-service groundwater-level tapes. The HIF routinely evaluates the performance of hydrologic equipment and instruments used by the USGS Water Mission Area to measure, record, and transmit hydrologic data. The performance of the equipment is primarily evaluated by the HIF for compliance to an accuracy requirement. Evaluation of instrument accuracy requires the HIF to develop or use established methods to check whether an instrument meets an accuracy specification. In some cases, these methods can be used to calibrate the equipment.

\section{Purpose and Scope}

The purpose of this study was to: (1) investigate tape calibration methods, and develop an accurate tape calibration method and device and (2) test the accuracy of a sample of USGS in-service steel and electric groundwater-level tapes using the calibration method and device. The report describes tape calibration and briefly reviews tape-calibration methods recommended by metrology laboratories and used by USGS WSCs. The selection criteria for the tape-calibration method are presented and the development of the tape-calibration method and device are described. Test data collected for a steel tape using the calibration method and device with a NISTtraceable, calibrated steel reference tape are used to determine the repeatability of the developed tape-calibration method.

Accuracy of USGS in-service steel and electric groundwater-level tapes was investigated by test calibrating a sample of tapes from various USGS WSCs. Fifteen in-service steel tapes from five WSCs and 14 in-service electric tapes from seven WSCs were tested for accuracy using the tapecalibration method and device. In-service tape test results are compared with the expected accuracy of \pm 0.01 foot (ft) per $100 \mathrm{ft}$. The accuracy tests for a sample of in-service steel and electric groundwater-level tapes using the tape calibration method are discussed and presented in tables and charts in the sections on the accuracy testing of in-service groundwater tapes.

\section{Overview of Tape Calibration and Tape Corrections}

A tape calibration compares the measurement by a test tape with a length reference of a known accuracy. A tape calibration can be used to verify that a tape is within its required accuracy or to produce a table of tape corrections or a tape correction equation. The comparison measurements are made at fixed intervals along the tape length and measure the length differences (or displacements) between the test tape and the length reference for each tape interval. For tapes of $100-\mathrm{ft}$ nominal length or greater, the chosen interval can be from 1 to $100 \mathrm{ft}$.

Tape corrections can be used to correct measurements made by a less accurate tape to meet accuracy requirements. The tape measurement, for the $i$ th interval, is corrected by:

$$
L_{\text {corrected }, i}=L_{\text {uncorrected }, i}+\Delta_{i},
$$

$$
\begin{aligned}
& \text { where } \\
& L_{\text {uncorrected, } i} \text { is the uncorrected tape measurement in feet, } \\
& \Delta_{i} \quad \text { is the measured length difference } \\
& \text { (displacement) or interval correction } \\
& \text { in feet, } \\
& L_{\text {corrected, } i} \quad \text { is the corrected tape measurement, and } i \\
& \text { indicates the } i \text { th-measured tape interval. }
\end{aligned}
$$

The displacement or interval correction, $\Delta_{i}$, is negative for a tape interval that is marked short, and is positive for a tape interval that is marked long.

A tape that is marked short will measure a longer distance to the water level than is actual. For example, during a calibration, the test tape measures $0.01 \mathrm{ft}$ shorter than the reference tape. Its measured correction is $-0.01 \mathrm{ft}$. In equation 1 , the minus correction will subtract the additional tape length, based on the tape markings needed to reach the water level. Similarly, a tape that is marked long will measure a shorter distance to the water level than is actual. For example, during a calibration, the test tape measures $1.00 \mathrm{ft}$ longer than the reference tape. Its measured correction is $+1.00 \mathrm{ft}$. If this tape makes a measurement in a well with a $100-\mathrm{ft}$ actual water level, the tape will read $99 \mathrm{ft}$. In equation 1, the positive correction will add the additional tape length, based on the tape markings, needed to reach the water level.

Tape corrections can be applied as a correction per foot of tape. A correction per foot of tape for the $i$ th tape interval, $\mathrm{c}(i)$, can be computed from: 


$$
c_{i}=\frac{\Delta_{i}}{L_{\text {uncorrected }, i}} \text {. }
$$

This equation assumes that the error is linearly distributed over the $i$ th measured interval and allows for unequal tape intervals. Table 1 is an example of a tape correction table.

A corrected tape measurement, $M_{\text {corrected }}$, is computed from the tape reading, $M_{\text {uncorrected }}$, in the $i$ th tape interval by:

$M_{\text {corrected }}=M_{\text {uncorrected }}+\left\{c_{n+1} \times\left[M_{\text {uncorrected }}-n I\right]+\sum_{i=1}^{n} \Delta_{i}\right\}$,

where

$$
\begin{gathered}
I \quad \text { is the calibration interval length } \\
\text { (for example, } 100 \mathrm{ft} \text { ), } \\
n \quad \text { is the number of complete intervals equal } \\
\text { to }\left(M_{\text {uncorrected }} \div I\right. \text { ) truncated to a whole } \\
\text { number, and }
\end{gathered}
$$

For example, the uncorrected measurement of $225.20 \mathrm{ft}$ using the electric tape with the correction information in table 1 is corrected as follows:

$$
\begin{gathered}
M_{\text {corrected }}=225.20+\{-0.00011 \times[225.20-(2 \times 100)]+0.0152\} \\
=225.20+(-0.02)=225.18 \mathrm{ft} .
\end{gathered}
$$

This correction is only for the tape markings and does not include the probe correction. Alternatively, a simpler to use, but potentially less precise, correction method is to use an equation obtained by fitting with linear regression the cumulative tape-marking corrections at each interval. Using an equation derived from linear regression, a corrected tape measurement, $M_{\text {corrected }}$, is computed from the tape reading, $M_{\text {uncorrected }}$, by:

$$
M_{\text {corrected }}=M_{\text {uncorrected }} \times\left(1+S_{\text {regression }}\right) \text {, }
$$

where $S_{\text {regression }}$ is the slope of the straight line regression equation fixed to the cumulative tape-marking corrections. For the fictional electric tape in table 1 , the regression slope, $S_{\text {regression, }}$, is $-0.00005 \mathrm{ft}$. The uncorrected measurement of $225.20 \mathrm{ft}$ is corrected as follows:

$$
M_{\text {corrected }}=225.20[1+(-0.00005)]=225.19 \mathrm{ft} .
$$

\section{Review of Tape Calibration Methods}

National and large professional metrology laboratories calibrate tapes similar to those used for groundwater-level measurement by laying out the tape to be calibrated on a flat, level surface and comparing it to a length reference whose accuracy (or uncertainty) has been evaluated. These laboratories use displacement-measuring interferometers to precisely measure the difference between the tape under calibration and the length reference. Displacement-measuring interferometers can have a resolution as small as $6 \times 10^{-9}$ inch (in.). Because of their high expense, calibration methods using displacement-measuring interferometers were not considered. Tape-calibration methods reviewed were limited to those using simpler displacement-measurement methods to measure the length differences between the test and reference tapes. Tape calibration methods using simpler displacement-measurement methods can be classified into two basic calibration methods: (1) the well measurement comparison and (2) the side-by-side tape comparison.

\section{Well-Measurement Comparison Calibration Method}

The well-measurement-comparison calibration method is described for electric tapes by Garber and Koopman (1968, p. 9) and is one of the electric-tape calibration methods listed by Cunningham and Schalk (2010, p. 35). The wellmeasurement-comparison calibration method is also described in internal USGS quality-assurance documents and used by some USGS offices.

The calibration method compares groundwater-level measurements made with the test tape (the tape to calibrate)

\begin{tabular}{|c|c|c|c|c|c|}
\hline$i$, interval & $\begin{array}{l}\text { Length } \\
\text { interval } \\
\text { in ft }\end{array}$ & $\begin{array}{c}\text { Actual } \\
\text { marked } \\
\text { length }\end{array}$ & $\begin{array}{l}\Delta_{i} \text {, interval } \\
\text { correction } \\
\quad \text { in } \mathrm{ft}\end{array}$ & $\begin{array}{c}\mathbf{c}_{\boldsymbol{i}} \text {, correction } \\
\text { over interval } \\
\text { in } \mathrm{ft} / \mathrm{ft}\end{array}$ & $\begin{array}{c}\text { Cumulative } \\
\text { correction } \\
\text { in } \mathrm{ft}\end{array}$ \\
\hline 1 & $0-100$ & 100 & -0.0130 & -0.000133 & -0.0130 \\
\hline 2 & $100-200$ & 100 & -0.0022 & -0.000022 & -0.0152 \\
\hline 3 & $200-300$ & 100 & -0.0110 & -0.000110 & -0.0263 \\
\hline
\end{tabular}
to measurements made with a steel reference tape in one or more wells of various depths to water. A steel tape water-level measurement requires chalking the end section of the tape. The steel tape groundwater-level measurement is determined by subtracting the length of the wetted chalk mark (the cut line) on the steel reference tape from the graduation value held at the top of the well (the hold) during the measurement (Cunningham and Schalk, 2011a, p. 6). The measurement difference between the test and reference tape (the displacement) is the tape correction for that tape length. Ideally, measurements

Table 1. Example of tape marking correction table for a fictional electric tape. 
Accuracy Testing of Steel and Electric Groundwater-Level Measuring Tapes: Test Method and In-Service Tape Accuracy

are made with the steel reference tape before and after the test tape measurement to account for any water-level changes in the well.

Calibration measurements at several wells can be combined to generate a tape correction curve that covers the range of measured water levels. Using only one calibration well reduces calibration time but assumes that the tape error is distributed in a linear manner over the tape length. This can cause significant measurement inaccuracies if the tape error is not linear.

A variation of the well-measurement-comparison calibration method utilizes a down-hole camera to compare the tapes in the well. This method permits a direct comparison of the tape readings. No tape chalking and reading of the cut line is needed. Major disadvantages of this variation are the extra expense required for the down-hole camera and the larger well-casing diameter required to permit the lowering and aligning of the reference and test tapes and a camera inside the well.

Accuracy of the well-comparison method is affected by the accuracy of the steel reference tape, the straightness of the well(s) casing, the range of water levels used for the calibration, and the changes in air temperature with location inside the well (usually very small). This method calibrates the test tape in field conditions and eliminates the need to apply tension to the tape during calibration. Differences in tensile load on the tape from tape construction and operation (steel versus electric) are automatically factored into the calibration measurement. For electric test tapes, the measurement difference between the test and reference tape includes any inaccuracy contributed by the operation and location of the water-level-indicating probe, as well as the length difference from the graduation-marking inaccuracies. The disadvantages of this method are as follows: (1) calibration time increases with the number of wells, (2) the reference tape is exposed to wear and tear, (3) test and reference tapes may not have identical alignment and distance down to the water surface, and (4) the calibration is not valid beyond the maximum depth of the measured wells. The method may require significant travel time to multiple wells.

\section{Side-by-Side Calibration Method}

The side-by-side-calibration method is described by American Society of Mechanical Engineers (ASME, 2009) and by NIST (NIST, 1986). The side-by-side calibration method is also described in internal USGS quality-assurance documents and used by some USGS offices. The ASME Standard B89.1.7 is intended for steel measuring tapes. The NIST Standard Operating Procedure (SOP) No. 12 for tape calibration (NIST, 1986) describes the method in detail for metal tapes used for land surveying and construction applications.

In general, the side-by-side-comparison calibration method compares the test tape to the reference tape while they are stretched out next to each other on a flat surface. It is similar to the method used by precision metrology laboratories to calibrate tapes. The method requires a location that has a flat, smooth, level surface that is slightly longer than (or a multiple of the calibration interval) needed to calibrate the tape. After the tapes are laid out side by side, they are aligned at the zero-interval marking or the graduation marking that is closest to zero. Usually, tension is applied to the tapes at the opposite end so that they lie flat. The displacement between the test-tape and the reference-tape interval graduation marks is measured at the opposite end. This displacement measurement is the measured difference between the test tape and the reference tape. Accuracy of this method is affected by the tensions applied to the test and reference tapes, tape temperature, accuracy of the reference tape, alignment of the test- and reference-tape marks at one end, resolution, and accuracy of the instrument used to measure the displacement and the closeness to parallel alignment of the tapes to each other.

One version of the side-by-side method used by USGS offices has one technician holding the tapes aligned to the lower interval gradation while another technician at the opposite end of the tapes pulls out the slack and measures the displacement between the next higher interval gradation (for example, the 100-ft mark) of the test and reference tapes. This version restricts the calibration interval to no longer than $100 \mathrm{ft}$, uses a steel reference tape, and measures only one displacement measurement for each calibrated tape interval. The method does not specify the amount of pull force to apply to the tapes, how to measure the displacement between the test tape and the reference tape, or require the measurement of the accuracy of the water-level probe.

The ASME document gives broad guidance on side-byside calibration methods. The guidance recommendations are to (1) apply a 10-pound (lb) tension to tape lengths less than or equal to $100 \mathrm{ft}$, (2) use a reference tape traceable to the NIST standards, and (3) use a comparator instrument, such as a measuring microscope, to measure the displacement between the test and reference tapes. The document also gives information on how to evaluate the accuracy of the calibration.

The NIST side-by-side calibration method calls for three replicated measurements between the tapes, with the tension released and reapplied after each measurement. NIST specifies a $10-1 \mathrm{~b}$ pull force for all steel tapes and millimeter $(\mathrm{mm})$ graph paper for measuring the displacement between the tapes. The accuracy of the calibration is limited by the graph paper to between 1 and $2 \mathrm{~mm}$ or $0.003 \mathrm{ft}$ and $0.006 \mathrm{ft}$. The NIST SOP (NIST, 1986) includes an explanation of using graph paper to measure the displacement between the test and reference tapes. Similar to the ASME document, the NIST documentation gives no recommendations on how to attach the scales to the tapes or how to anchor the other tape ends.

There are advantages and disadvantages to the side-byside comparison. The side-by-side method can be very accurate and repeatable. Because it can be conducted either in a long office hallway or outdoors on a level area, it does not require access to a number of wells or special equipment. The advantages are excellent repeatability, small likelihood of 
reference tape damage, fast calibration times, and the entire tape length can be calibrated. The disadvantages are (1) long tapes must be calibrated in intervals, which increases calibration time and potential error; (2) two technicians or specialized equipment are needed; (3) different pull forces may be needed for tapes of different construction, such as electric tapes; (4) pull forces may not equal the tape tension during a well measurement; and (5) the measurement inaccuracy contributed by the probe is not measured.

\section{Tape Calibration Requirements}

The calibration method accuracy needed for groundwater-level measuring tapes should be better than the expected accuracy of the groundwater-level tapes $(0.01 \mathrm{ft})$. Additionally, WSCs should be able to use the method to perform groundwater-tape calibrations at their offices and the method should not be cost prohibitive.

Cost and effort of a calibration method is directly affected by the calibration accuracy requirements. USGS Techniques and Methods 1-A1, "Groundwater Technical Procedures of the U.S. Geological Survey" states that steel and electric tapes are commonly accurate to $0.01 \mathrm{ft}$ (Cunningham and Schalk, 2011a, 2011b; p. 8, 35, 37). Based on traditional metrology requirements (International Standards Organization, 1992; ISO 10012-1) for test accuracy ratio, the reference tape should have an accuracy that is one-third to one-quarter of the accuracy of the tape being calibrated. This requires the reference tape to have an accuracy of better than $0.0033 \mathrm{ft}$ to meet an accuracy of $0.01 \mathrm{ft}$. However, the test accuracy ratio does not explicitly include calibration test errors that come from sources other than the reference tape. Ideally, to meet a measurement accuracy of $0.01 \mathrm{ft}$, the accuracy of the overall calibration method should be better than $0.0033 \mathrm{ft}$.

The law of propagation of uncertainty, as presented in the International Standards Organization's Guide to Expression of Uncertainty in Measurement (GUM, 1993), can be used to estimate the accuracy of the displacement measurement (length difference) and the reference tape needed to meet the 3-to-1 test accuracy ratio. An estimate for the combined standard uncertainty, $\mathrm{u}_{\Delta}$, of the calibration is:

$$
u_{\Delta}=\left[u_{\text {reference }}^{2}+u_{\text {displacement }}^{2}\right]^{1 / 2}
$$

$$
\begin{gathered}
\text { where } \\
u_{\text {reference }}^{2} \\
\begin{array}{c}
\text { is the standard uncertainty of the calibrated } \\
\text { reference tape, and }
\end{array} \\
\begin{array}{c}
\text { is is the standard uncertainty of the } \\
\text { displacement measurement. }
\end{array}
\end{gathered}
$$

Assuming that the resolution of the displacement measurement and the reference tape bound the uncertainty of those sources of calibration uncertainty, an estimate of the calibration uncertainty can be computed. Both of these assumptions may be optimistic, but give a ball park estimate of the calibration uncertainty using various measurement devices. Because the resolution of each uncertainty source is assumed to have a rectangular distribution and bound the uncertainty, the resolution is divided by $\sqrt{ } 3$ to give the standard deviation, which is equal to the standard uncertainty. If a steel reference tape, with a calibrated accuracy of $0.001 \mathrm{ft}$, and 1-mm graph paper are used to calibrate a tape, the estimated combined standard uncertainty using equation 5 is:

$u_{\Delta}=\left[\left(\frac{0.005 \mathrm{ft}}{\sqrt{ } 3}\right)^{2}+\left(\frac{1 \mathrm{~mm} \times 0.0032808 \mathrm{ft} / \mathrm{mm}}{\sqrt{ } 3}\right)^{2}\right]^{1 / 2}=0.02 \mathrm{ft}$,

and is equal to an acceptable test ratio of 1 to 5 . This estimate ignores any uncertainty contributed by temperature differences between the two tapes, tensioning errors, uneven calibration surfaces, or test repeatability.

\section{Recommended Calibration Method}

The recommended calibration method for groundwaterlevel measurement tapes is a side-by-side method. The sideby-side calibration method was selected because it allows for the entire tape length to be calibrated, is recognized by NIST and ASME as a method that can be used to calibrate tapes similar to those used for groundwater-level measurements, and does not require a large investment in equipment or access to wells to perform. The recommended calibration method is a modified version of NIST SOP No. 12 "Tape-to-Tape Method" (NIST, 1986) and is applicable to steel and electric groundwater-level tapes. This modified NIST method, along with a custom-designed and fabricated calibration device (not required but very helpful), forms the calibration system used by this study to test the accuracy of in-service tapes.

The equipment needed for the side-by-side tape calibration includes: (1) a NIST-traceable steel tape calibrated to an appropriate accuracy; (2) equipment or person to anchor one end of the tapes (for example, surveying tape clamp handle, and stake(s), concrete screws, surveying pins, or weights); (3) two tape tension handles (for example, Lufkin 586 30-lb tape handle) or scales to apply accurate pull forces to the tapes; (4) graph paper or some other means to measure the displacement between the test and reference tapes, and (5) an appropriate flat test area that is at least $50 \mathrm{ft}$ long (preferably longer). Alternatively, a calibration device designed for tape calibration can be substituted for items 2 through 4 .

Additionally, at least one technician (possibly two, depending on equipment used) is needed. A worksheet for recording all necessary calibration information, including tape information, calibration information, and correction calculations for the calibration method, is in appendix 1. 


\section{Reference-Tape Requirements}

The reference tape should be a steel tape at least $100 \mathrm{ft}$ long. The calibrated length of the reference tape should be at least $100 \mathrm{ft}$ long but may be less than the total length of the reference tape. The calibrated length of the reference tape should have a NIST-traceable calibration to at least $\pm 0.001 \mathrm{ft}$ or better. The reference tape should not be used for routine water-level measurements and should be handled and stored carefully to preserve the tape accuracy.

\section{Displacement-Measurement Requirements}

The equipment or materials used to measure the displacement between the test and reference tape graduations should have a resolution of at least $0.0033 \mathrm{ft}(0.04 \mathrm{in}$. or $1 \mathrm{~mm}$ ). Graph paper marked in centimeter and millimeter graduations can be used as described in the NBS SOP 12 (NIST, 1986). Graph paper has the advantage of having lines that can be used to ensure that the test and reference tapes are aligned properly. Alternatively, calibrated digital calipers, or a precision steel rule marked in $1 / 32$-in. (or $0.5-\mathrm{mm}$ ) increments can be used to measure the displacement. Measuring the displacement in length units other than feet is acceptable, but requires the units to be converted into feet.

\section{Calibration-Interval and Test-Location Requirements}

The ideal test location is indoors in a hallway or warehouse. This will provide temperature stability and eliminate solar heating. Alternatively, an outdoors test location with a smooth, level surface, such as concrete or asphalt, is acceptable on a cloudy day. The clouds will minimize solar heating of the tapes. As long as there are no bumps or dips, a concrete or asphalt surface, such as a parking lot or sidewalk, will be acceptable. Conditions that create unacceptable calibration accuracy include outdoors on a sunny day or a gravel or grass surface. The sun will heat the tape in an uncontrollable and irregular manner and will cause substantial errors. A gravel or grass surface is irregular and the tapes will likely take slightly different paths, causing random errors. A temperature correction is not necessary if the reference and test tapes are allowed to equalize with the test location ambient temperature. However, temperature differences between the reference and test tapes can be a significant source of test error, especially if the test and reference tapes are made of different materials. A difference in temperature by $2{ }^{\circ} \mathrm{C}$ between steel tapes gives a calibration measurement error of $0.0023 \mathrm{ft}$ (Moffit and Bouchard, 1975).

The recommended calibration interval is $100 \mathrm{ft}$. Shorter calibration intervals introduce additional time and technician error with each tape reset for the measurement of the next interval section. However, good calibrations are possible with a shorter interval, such as a $50-\mathrm{ft}$ calibration interval in a $60-\mathrm{ft}$ hallway. The measurement uncertainties from the shorter calibration interval and the increased number of measurements in the controlled environmental conditions in an office hallway are small compared to the uncertainties from solar heating and unknown surface irregularities of a grass field or gravel driveway.

\section{Tape Tensioning}

Ideally, a calibrated scale pulled mechanically should be used to tension the tapes during calibration. It will assure calibration accuracy and repeatability. Pulling the tapes by hand without any force measurement device does not allow an accurate pull force to be consistently applied. A portable scale, such as a fishing scale, pulled manually is acceptable as long as the technician pulling the scales can maintain the pull forces during the measurement and repeat the same pull for each measurement. The scales or tape-tension handles should have an accuracy of $\pm 0.5 \mathrm{lb}$ or better, resolution of $\pm 0.5 \mathrm{lb}$, and a range of 0 to $20 \mathrm{lbs}$. For steel tapes, a weight-scale accuracy and resolution of $0.5 \mathrm{lb}$ gives a possible calibration error of $0.000672 \mathrm{ft}$ (Moffit and Bouchard, 1975).

\section{Steel tapes}

A standard pull force of $10 \mathrm{lbs}$ is prescribed during calibration for all steel tapes over a 25 - to $100-\mathrm{ft}$ calibration interval. This is the tension force used by NIST and ASME for steel tape calibrations. If no weight is attached, a steel tape would require at least $1,200 \mathrm{ft}$ to be lowered down a well to achieve about $20 \mathrm{lbs}$ of tensile force at the very top of the tape. If weight is attached to the tape, usually a few ounces or a couple of pounds, the tensile force at the top of the tape is increased by the amount of the attached weight. Steel tapes that are lying flat and are not bent or crimped can handle tensile forces exceeding $50 \mathrm{lbs}$ without permanent damage.

\section{Electric Tapes}

A standard tension does not apply to the calibration of electric tapes. Because the probe on most electric tapes also acts as the weight, the tape down tension is constant and known. Precision scales can apply a simulated weight of the electric-tape probe and tape as a function of length. This provides the most realistic calibration as the tension applied is approximately the same as the actual in-use tension for each tape section. Tape tension increases linearly with length. The in-use down-hole tension for an electric tape is the calculated average tension over the calibration interval. The calibration tension for the 100 - to $200-\mathrm{ft}$ calibration interval is equal to the weight of the probe plus the weight of the 0 - to $100-\mathrm{ft}$ tape interval plus one half of the weight of the 100 - to $200-\mathrm{ft}$ tape calibration interval. Table 2 lists tensions to apply during electric-tape calibrations for tape calibration intervals from 100 - to $500-\mathrm{ft}$ for several electric-tape models. As long as the 
Table 2. Electric groundwater-level measuring-tape probe and tape weights for various models and calibration tensions by tape interval used to simulate in-use tensions.

\begin{tabular}{|c|c|c|c|c|c|c|c|}
\hline \multirow[t]{2}{*}{ Model } & \multirow{2}{*}{$\begin{array}{c}\text { Probe } \\
\text { weight (lbs) }\end{array}$} & \multirow{2}{*}{$\begin{array}{c}\text { Tape weight } \\
\text { per ft (lbs) }\end{array}$} & \multicolumn{5}{|c|}{ Calibration tension by interval } \\
\hline & & & 0 to $100 \mathrm{ft}$ & 100 to $200 \mathrm{ft}$ & 200 to $300 \mathrm{ft}$ & 300 to $400 \mathrm{ft}$ & 400 to $500 \mathrm{ft}$ \\
\hline $\begin{array}{l}\text { Solinst Model } \\
\quad 101\end{array}$ & 0.322 & 0.0107 & 0.86 & 1.92 & 2.99 & 4.06 & 5.13 \\
\hline $\begin{array}{l}\text { Solinst Model } \\
\quad 102\end{array}$ & 0.142 & 0.0105 & 0.67 & 1.72 & 2.77 & 3.82 & 4.87 \\
\hline DGSI & 0.123 & 0.0121 & 0.73 & 1.94 & 3.15 & 4.35 & 5.56 \\
\hline RST Model 3001 & 0.169 & 0.0127 & 0.80 & 2.07 & 3.34 & 4.62 & 5.89 \\
\hline Heron Dipper-T & 0.352 & 0.0134 & 1.02 & 2.37 & 3.71 & 5.06 & 6.40 \\
\hline InSitu 200 & 0.352 & 0.0134 & 1.02 & 2.37 & 3.71 & 5.06 & 6.40 \\
\hline $\begin{array}{l}\text { Geotech Keck } \\
\text { Water Level }\end{array}$ & 0.339 & 0.0137 & 1.02 & 2.39 & 3.76 & 5.13 & 6.50 \\
\hline Waterline & 0.434 & 0.0085 & 0.86 & 1.71 & 2.57 & 3.42 & 4.27 \\
\hline
\end{tabular}

tape elongation is linear (assumed in all tape calibrations), an average tension applied horizontally will cause the same stretch as the tape suspended vertically down a well.

\section{Basic Calibration Steps}

The basic steps of the proposed calibration procedure are:

1. Acclimate the reference and test tapes to the temperature of the test area. Allow the tapes at least 1 hour or longer for larger initial differences in temperature between the tapes and the ambient temperature in the test area before beginning calibration.

2. Record test date, tape identification numbers, test personnel names, and test location on the calibration record sheet. Also, record the average surface temperature and ambient air temperature. The test conditions should also be recorded, such as weather (if outdoors) and test surface conditions. Record the calibrationinterval information, the calibration interval used, and the number of intervals in the tape. Calibrating a 1,000-ft tape with a 100-ft interval would need 10 100-ft interval measurements. Record the type of instrument and its accuracy used to measure the displacement between test and reference tapes graduation markings and the units of the measurement on the calibration sheet.

3. Clear the test area of any dirt and debris. The test area should be a reasonably level, hard surface, such as a smooth asphalt road, a concrete floor, or a carpeted hallway. Any bumps or irregularities should affect both tapes equally, or measurement errors could occur.

4. Roll out the test and reference tapes parallel to each other with the graduations face up and increasing in the same direction. Inspect the tapes for any damage, such as kinks or curling that would make either of them unusable and note the location of any damage. If the reference tape is damaged, do not proceed with the calibration. Record information on the test and reference tape condition.

5. Attach one end of each of the tapes to a mechanical system fixed to the ground or use a technician to hold the tapes in position. Tapes should be clamped with either specialty surveying tape clamps or with clamps having rubber-padded jaws.

6. Attach each of the other tape ends to scales (one for each tape) either attached to a mechanical pull system or use a technician to hold and pull the scales.

7. Ensure that the anchor and puller are square with the tapes and each other, the tapes are parallel, and the tape markings aligned precisely on the anchor side. Misalignment of either the tapes or the tape markings at the anchor end will adversely affect the calibration accuracy.

8. Apply an initial tension of 15 or $20 \mathrm{lb}$ and "snap" the tapes until they are straight and parallel with each other. The tapes should be plucked with a vertical motion (just like plucking a chalk line) a few times to get the tapes to settle into parallel, straight lines. The "snap" does not need to be violent.

9. Reduce the tension in the reference tape to $10 \mathrm{lb}$ (standard tension) to give the calibrated length of the reference tape.

10. Reduce the tension in the test tape to $10 \mathrm{lb}$ (steel tape) or the desired in-use tension (electric tape). The in-use tension is typically used for electric tapes and is the average tension on that tape interval during a wellwater-level measurement, one-half the weight of the tape interval being calibrated. 
11. Check the alignment of the tapes at the anchor end and make adjustments as needed. After any tape position correction, check the tension forces and adjust as needed to the required tension. Record the actual tension forces for both the reference tape and the tape under calibration on the calibration sheet.

12. Measure the displacement between the test and reference tapes interval graduations using digital calipers, precision steel ruler, or graph paper (NIST, 1986) to determine the displacement (or difference) in the tape lengths. Record the tape displacement measurement on the calibration record sheet.

13. Switch the tapes' positions. For example, if the reference tape is on the right side and the test tape is on the left, switch them so that the reference tape is on the left side and the test tape is on the right.

14. Repeat steps 5 through 13 until there are four measurements made over the segment (two measurements in each of two positions). If two measurements over the same interval differ by more than twice the accuracy of the measurement, repeat the interval measurement. Average the four good measurements for the interval to determine the accuracy of the test tape over that interval.

15. Repeat steps 5 through 14 for each interval of tape until the entire tape calibration is completed.

After the calibration is completed, roll up the test and reference tapes. Store the reference tape in a protective case and a dry, secure location. The test tape can be put into service if its calibration is within its expected accuracy or if the resulting correction table gives corrections that are within its expected accuracy. Groundwater tapes are usually expected to have an accuracy of better than $0.01 \mathrm{ft}$ or 0.01 percent over any tape interval, whichever is largest. If the test tape is kinked or curled, the tape is permanently deformed and should be removed from service. However, it may be possible to remove the deformed section to allow the shortened tape to be recalibrated and returned to service. If the test tape conditions are unacceptable, label it as unusable and plan to dispose of the test tape.

\section{Calibration Device}

A calibration device was designed and constructed to reduce the time and effort needed to align and tension the tapes during calibration using the side-by-side method. The device was also constructed to be easy to move and store.

The calibration device has two parts, an anchor and a tensioner. Both the anchor and the tensioner were constructed to give a fixed, stable platform on which to attach the tapes.
The anchor is used to hold the tape ends that are aligned to a common interval graduation. The tensioner is used to apply tensions on each tape and includes two scales to measure the applied tensions. The weight scales (CCI Scale Company, Inc. model HS-30) installed on the tensioner have a resolution of $\pm 0.02 \mathrm{lb}$. Weights are placed on the anchor and tensioner to hold them in place when the tape is tensioned.

Two calibration devices were constructed during the study. The first design, CD1, was used for initial method testing with in-house steel tapes. Two people were used to operate the first device. The first anchor design used a single screwdown rubber-coated clamp to hold both tapes and a machinist's square to align the graduation marks. The first tensioner design attached the tape to the scales with rubber-surface cam assemblies. The cam assemblies rode on linear rails and were attached with ropes to the scales. A rope-and-pulley system was used to apply the tension to the tapes. Tape tension was fixed by positioning the ropes in spring-loaded cleats. The displacement between the test and reference tapes graduation marks was measured with a dial caliper. The initial design was functional but had several problems. The design made applying two different tape tensions difficult because of the single tape clamp on the anchor. The stretchiness of the ropes made tension adjustment time consuming because the ropes would relax after the initial tension was applied, requiring additional adjustment. Additionally, the dial caliper required patience, as well as skill to align with the tape graduations, and the thickness of the anchor and tensioner added a small amount of tape sag near the anchor and tensioner.

The first design was modified and a new calibration device, $\mathrm{CD} 2$, was built to improve the initial design and calibration efficiency. The CD2 anchor (fig. 1A) has two toggle clamps for individual tape adjustment, and milled lines to aid in tape graduation alignment. The CD2 tensioner (fig. 2) uses a chain and acme screw system instead of the original ropeand-pulley system. The chain and acme screw system (fig. 2C) allows for coarse (chain) and fine (acme screw) tension adjustment, and the tapes to be individually and rapidly tensioned. The tensioner has a pair of rollers that holds the tapes close to the ground as they come off the device to minimize tape sag from the anchor and tensioner (figs. $2 B$ and $2 C$ ). An integrated, custom, moving Vernier scale was installed in the tensioner to measure the displacement between the test and reference tapes (figs. $2 B$ and $2 C$ ). The Vernier scale allows displacement measurements with a resolution of $0.0005 \mathrm{ft}$. A single technician can efficiently operate the device, but placing a technician at each end eliminates the need to walk back and forth between the anchor and the tensioner and reduces calibration time. 


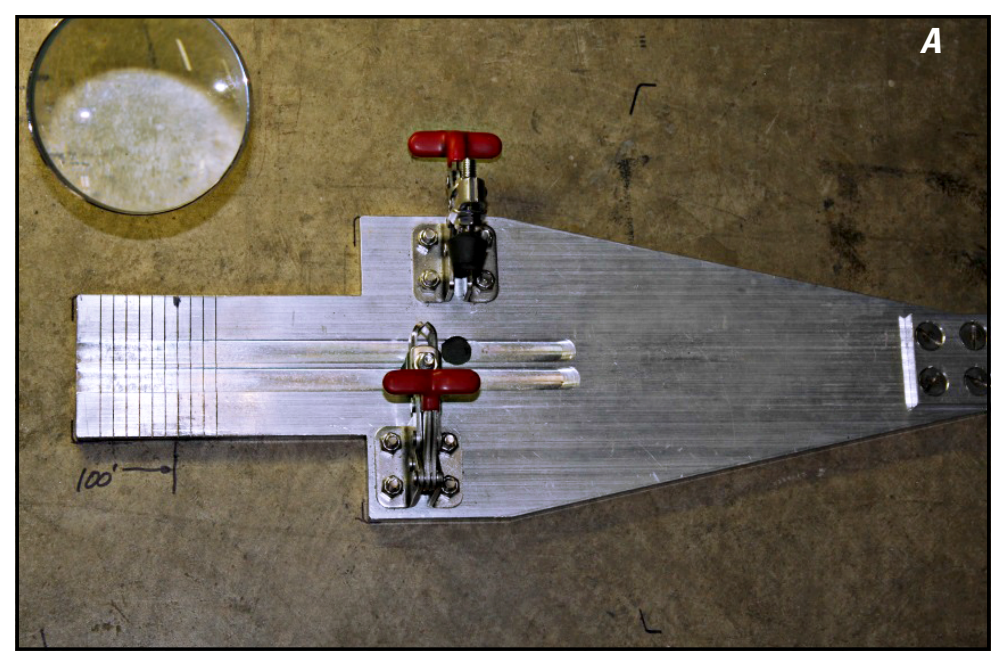

Figure 1. Calibration Device 2 anchor. $A$, Overhead view of anchor showing toggle clamps and tape alignment lines. $B$, Tape end view of anchor with weights piled onto plate to hold anchor to floor during tape tensioning.
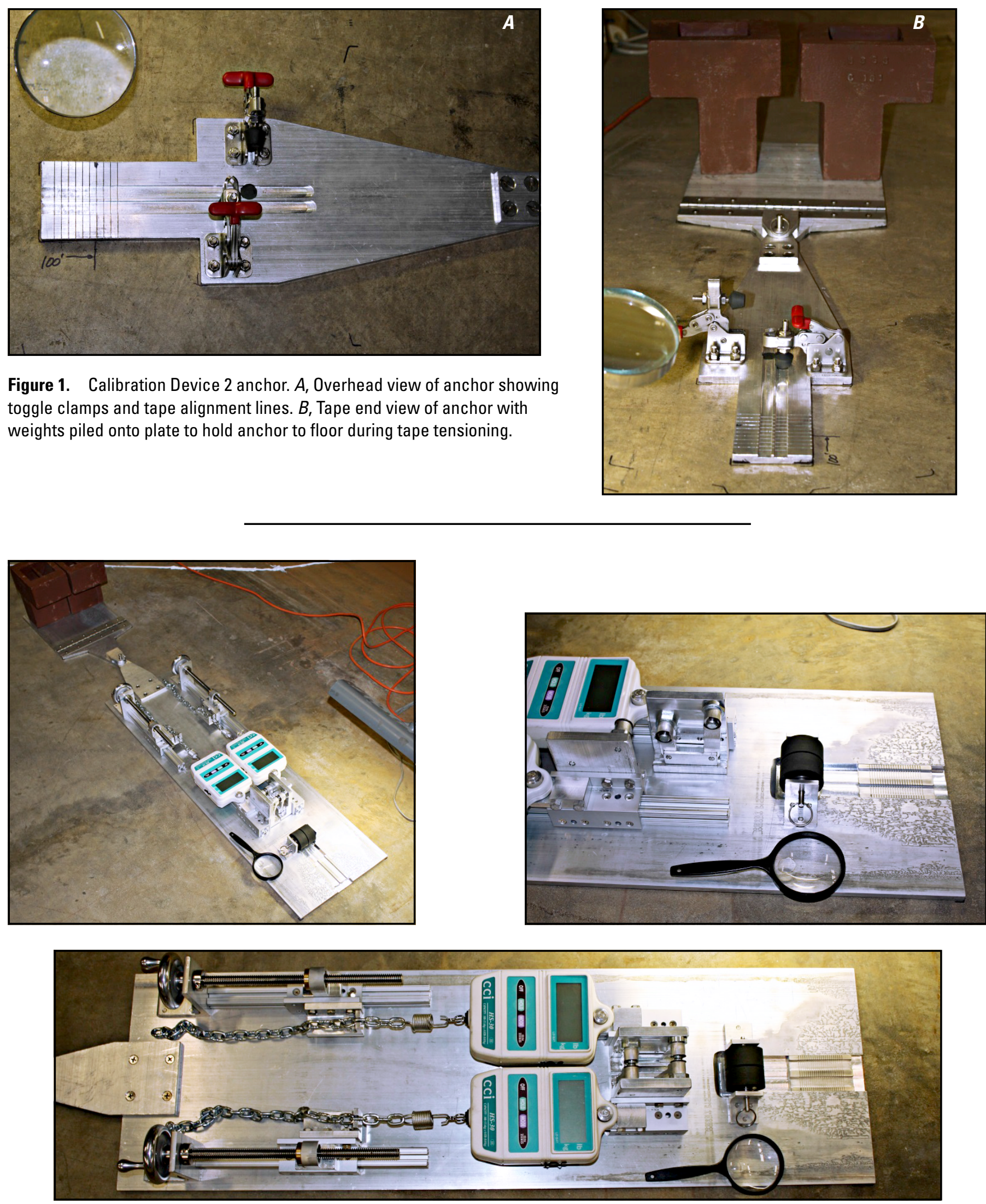

Figure 2. Calibration Device 2 tensioner. $A$, Overhead view of tensioner showing plate with weight to hold tensioner to floor during tape tensioning. $B$, View of tape grippers, roller, and Vernier scale. $C$, Close-up overhead view showing chains for coarse tension adjustment and acme screws for fine-tension adjustment and two weigh scales used to measure applied tension. 


\section{Displacement Measurement using the Vernier Scale}

A Vernier scale is composed of two scales, one fixed and one moving. The moving Vernier scale slides past the fixed one, and indicates a higher precision measurement in-between the marks of the fixed scale. In the case of the CD2, the fixed scale is the tape graduations of the reference tape. At the anchor end, the reference tape 101-ft graduation mark is aligned with the interval graduation mark (for example, the 100 -ft mark) of the test tape. The displacement measurement is made at the puller end using the custom moving Vernier scale (figs. 3 and 4) as follows:

1. Align one of the moving Vernier scale grooves to the interval graduation mark on the test tape. If the interval graduation mark of the test tape is closer to the anchor end than the 1-ft mark of the reference tape, the test tape is short and the displacement is negative. If the interval graduation mark of the reference tape is closer to the anchor end than the interval graduation mark of the test tape, the test tape is long and the displacement is positive.

2. Make the coarse measurement by counting the $0.01-\mathrm{ft}$ tape graduation marks on the reference tape, $\mathrm{j}$, between the two tapes' interval marks (100-ft, $200-\mathrm{ft}$, and so on). The count, $\mathrm{j}$, is multiplied by $0.01 \mathrm{ft}$ to give the coarse measurement.

3. Make the fine measurement by counting the number of moving scale grooves, $\mathrm{k}$, from the scale groove aligned to the test tape interval graduation mark in step 1 to the scale groove that aligns with a $0.01-\mathrm{ft}$ mark on the reference tape. If the test tape interval is short, count the scale grooves to the right of the aligned groove. If the test tape interval is long, count the scale grooves to the left of the aligned groove. The Vernier moving-scale groove count is multiplied by $0.0005 \mathrm{ft}$ to give the fine measurement.

4. Compute the displacement by adding the fine measurement to the coarse measurement $(\mathrm{k} \times 0.01+\mathrm{j} \times 0.0005)$.

5. Determine the sign of the displacement. If the test tape interval graduation mark is closer to the anchor than the reference tape mark, the difference is negative. If the test tape interval graduation mark is farther from the anchor than the reference tape mark, the displacement is positive.

Determining the displacement measurement after aligning the Vernier groove to the test-tape interval mark is not difficult. For example, figure 3 shows the displacement measurement for the 100- to 200-ft interval of a steel test tape. In figure 3, the anchor is to the right of the photo and the test tape is the upper tape in the figure. The test tape 200 -ft graduation mark has been aligned with the 101-ft graduation mark of the steel reference tape at the anchor. The reference tape in figure 3 is the tape showing the 1-ft graduation mark. The Vernier groove has been aligned to the test tape 100-ft interval graduation mark.
The test tape is short because the test tape interval graduation mark is closer to the anchor than the reference tape 1-ft graduation mark. To determine the displacement measurement using figure 3:

1. Count the number of $0.01-\mathrm{ft}$ graduation markings that are between the reference tape's 1-ft interval graduation mark and the test tape's 100-ft interval graduation mark. The interval graduation markings for the tapes are within $0.01 \mathrm{ft}$ of each other, indicating that the displacement is less than $0.01 \mathrm{ft}$ and the coarse measurement is zero.

2. Because the test tape interval is short, count the number of Vernier grooves to the right of the test tape's $100-\mathrm{ft}$ mark until the Vernier grooves align with a $0.01-\mathrm{ft}$ mark on the reference tape. It takes five Vernier groove marks to align the Vernier grooves with a $0.01-\mathrm{ft}$ mark on the reference tape, so the fine measurement is $5 \times 0.0005=0.0025 \mathrm{ft}$.

3. Sum the coarse and fine measurements, $0+0.0025=0.0025 \mathrm{ft}$.

4. Determine the sign of the correction. The test tape is shorter than the reference tape and the correction becomes $-0.0025 \mathrm{ft}$ for this interval section of the test tape.

Figure 4 shows the displacement measurement for the 100- to 200-ft interval of a test electric tape. As in figure 3, the anchor is to the right of the photo, but the reference tape is at the top of the figure. The test tape $200-\mathrm{ft}$ graduation mark is aligned with the reference tape $101-\mathrm{ft}$ graduation marks at the anchor. As in the previous example, the test tape is short because the test tape 100-ft interval graduation mark is closer to the anchor than the reference tape 1-ft graduation mark. The Vernier groove has been aligned to the test electric-tape 100-ft interval graduation mark. To determine the displacement using figure 4:

1. Count the number of $0.01-\mathrm{ft}$ graduation markings that are between the reference tape's 1-ft graduation interval mark and the test tape's $100-\mathrm{ft}$ interval mark. The test and reference tapes' interval graduation marks are separated by two $0.01-\mathrm{ft}$ increments. The coarse measurement is $2 \times 0.01=0.02 \mathrm{ft}$.

2. Because the test tape is short, count the number of Vernier grooves to the right of the electric-tape $100-\mathrm{ft}$ mark until the Vernier grooves align with a $0.01-\mathrm{ft}$ mark on the reference tape. A count of one aligns the Vernier groove with a $0.01-\mathrm{ft}$ mark on the reference tape. The fine measurement is $1 \times 0.0005=0.0005$.

3. Sum the coarse and fine measurements: $(2 \times 0.01)+(1 \times 0.0005)=0.0205 \mathrm{ft}$.

4. Determine the sign of the correction. Because the test tape is shorter than the reference, the tape correction is $-0.0205 \mathrm{ft}$ for the tape in figure 4 . 


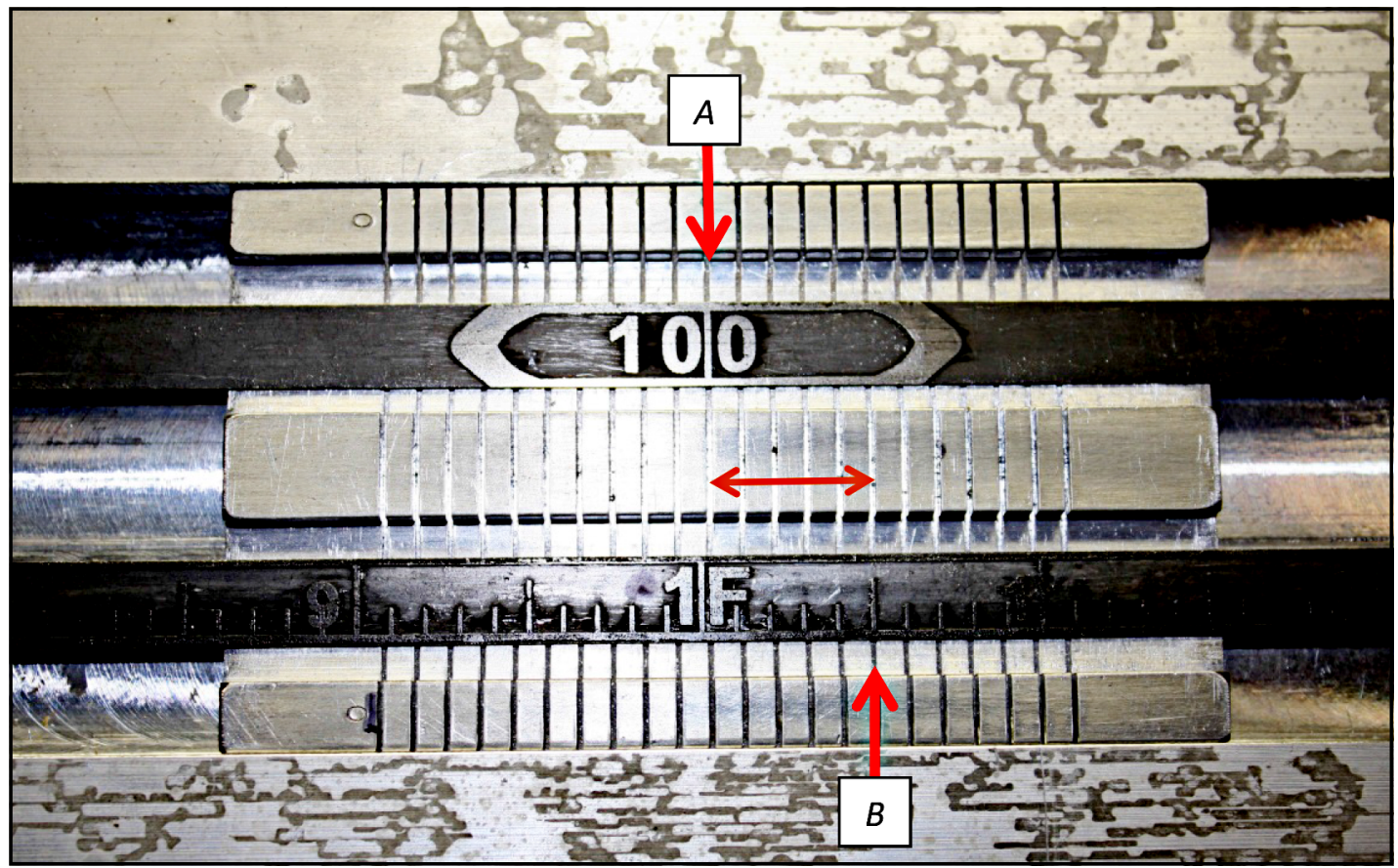

Figure 3. Close-up view of Vernier scale during displacement measurement of a steel test tape (top tape) with a steel reference tape (bottom tape). Red arrow, $A$, points to the alignment of the moving Vernier scale groove to the test-tape intervalgraduation mark. No 0.01 -foot (ft) marks are between the 100-ft and 1-ft graduation marks, giving a count of " 0 " for the coarse measurement. Red arrow, $B$, points to the Vernier scale groove that aligns with the reference tape 0.01 - $\mathrm{ft}$ graduation mark. The double-head arrow line indicates the five grooves to count for the fine measurement.

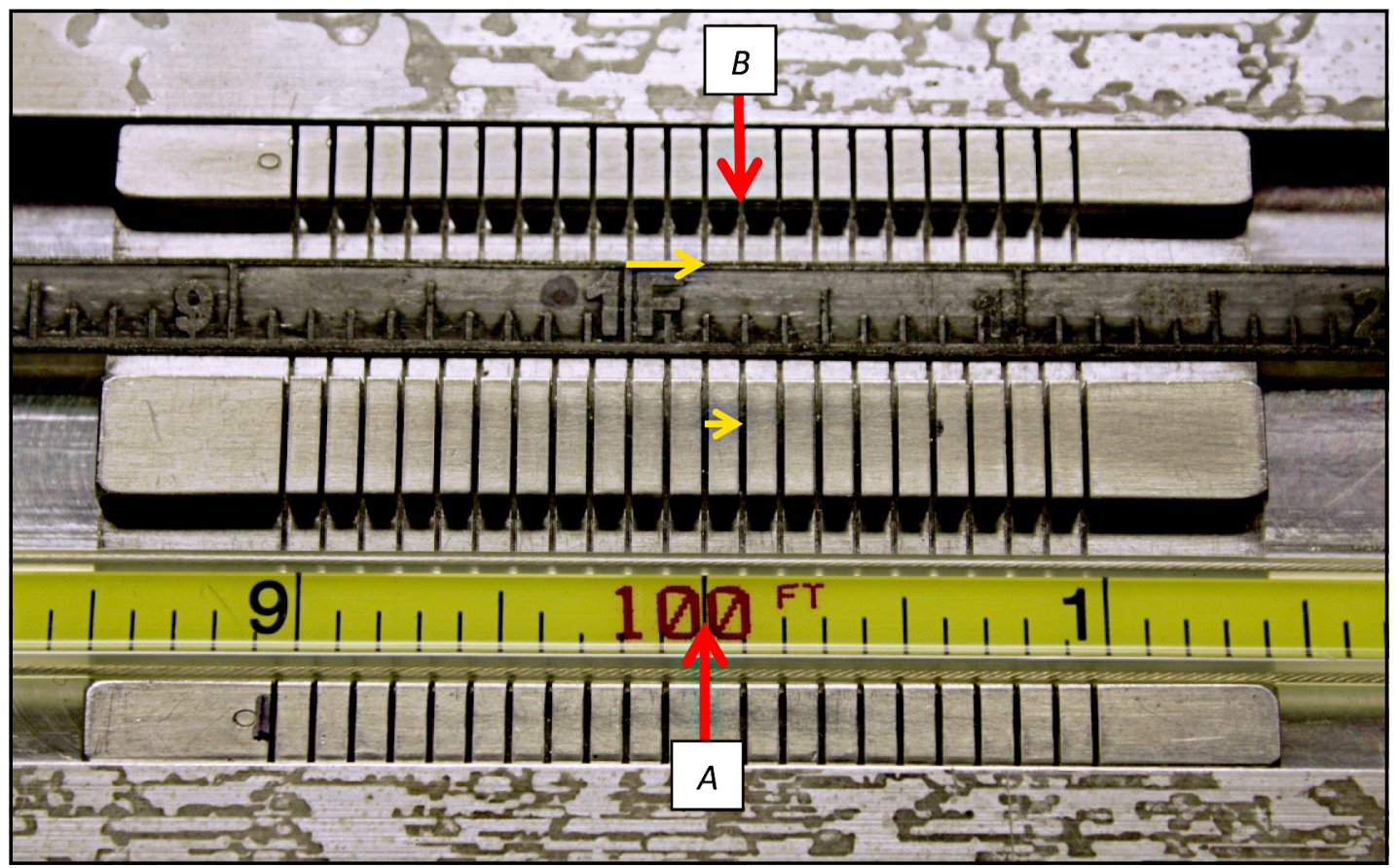

Figure 4. Close-up view of Vernier scale during displacement measurement of an electric test tape (bottom tape) with a steel reference tape (top tape). Red arrow, $A$, points to alignment of the moving Vernier scale groove to the test-tape intervalgraduation mark. Two $0.01-\mathrm{foot}(\mathrm{ft})$ marks, denoted by the larger orange arrow, are between the $1-\mathrm{ft}$ and $100-\mathrm{ft}$ graduation marks, giving a count of 2 for the coarse measurement $(0.02 \mathrm{ft})$. Red arrow, $B$, points to the Vernier scale groove that aligns with the reference tape $0.01 \mathrm{ft}$ graduation mark. The smaller orange arrow indicates the " 1 " groove to count for the fine measurement of $0.0005 \mathrm{ft}$. 


\section{Estimated Calibration Improvement Using Calibration Method Indoors with Calibration Device}

For a calibration conducted outdoors without the CD2, the expanded uncertainty of a calibration (International Organization for Standardization, 1993) estimated by:

$$
U_{\Delta}=2 \times\left[u_{\text {reference }}^{2}+u_{\text {displacement }}^{2}+u_{\text {tension }}^{2}+u_{\text {temperature }}^{2}\right]^{1 / 2},
$$

assuming a displacement measurement accuracy of $1 / 32$ in. $(0.0033 \mathrm{ft})$, a reference tape accuracy of $0.001 \mathrm{ft}$, an error of $0.0003 \mathrm{ft}$ due to tensioning accuracy of $\pm 0.5 \mathrm{lb}$, and an error of 0.0023 due to a 2 degree Celsius $\left({ }^{\circ} \mathrm{C}\right)$ difference between the test and reference tapes, is $0.005 \mathrm{ft}$. The expanded uncertainty has a 95-percent confidence interval in comparison to the standard uncertainty, which has a 66-percent confidence interval. The individual calibration errors and accuracies are assumed to have a rectangular distribution and are divided by $\sqrt{3}$ to give the standard deviation, $u$, which is used in the uncertainty calculation. For a calibration conducted indoors with the CD2, the expanded uncertainty of a calibration uncertainty (International Organization for Standardization, 1993) estimated by assuming a NIST-traceable reference tape calibrated to $+/-0.0001 \mathrm{ft}$, a displacement measurement accuracy of 0.0005 $\mathrm{ft}$, an error of $0.0001 \mathrm{ft}$ due to tensioning accuracy of $\pm 0.2 \mathrm{lb}$, and no error from temperature differences, is $0.001 \mathrm{ft}$.

\section{Repeatability of Calibration Method with Calibration Device}

The repeatability (or precision) of the calibration method using the calibration device was determined by comparing a calibrated reference tape to the test tape, a new 300 -ft Lufkin, Super Hi-way Nubian steel tape, and computing the standard deviation from a number of repeated tests. The calibrated reference tape used for the calibrations was also a 300-ft Lufkin, Super Hi-way Nubian steel tape. The calibrated steel reference tape is NIST-traceable and was calibrated by Lockheed Martin-Stennis Integrated Metrology Center, a metrology laboratory that is ACLASS accredited to ISO 17025. The reference tape total error over the $100-\mathrm{ft}$ test section is $0.00092 \mathrm{ft}$.

All test calibrations were conducted indoors on a level, smooth concrete floor in the HIF Hydraulic Laboratory. The calibration interval used for the testing was $100 \mathrm{ft}$. Prior to testing, the tapes were acclimated to the ambient air temperature in the Hydraulic Laboratory. During the testing, the maximum and minimum air temperatures observed in the Hydraulic
Laboratory were 29.6 and $27.7^{\circ} \mathrm{C}$, respectively. Because the tapes were equalized to the ambient air temperature over several hours and both tapes are of the same material, the dimensional differences between the tapes due to temperature was negligible and no temperature corrections were necessary.

Measurements were taken over the entire $300-\mathrm{ft}$ length of test tape and compared to the $100-\mathrm{ft}$ calibrated interval of the reference tape. Each calibration required 12 displacement measurements; four repeated measurements per 100-ft tape interval over the $300-\mathrm{ft}$ test-tape length. A total of 10 calibrations were conducted using a total of 120 interval measurements. Table 3 lists the summary statistics for all of the individual interval measurements made during the repeated calibrations. Based on the standard deviation computed from the individual interval displacement measurements, any single interval measurement made with the calibration device has a standard uncertainty (or standard deviation) of $0.0011 \mathrm{ft}$. Table 4 lists the summary statistics for the 10 repeated tape calibrations. Each interval measurement for a calibration is the average of four measurements and the statistics in table 4 are for those interval measurements. The statistics are similar to those listed in table 3.

Reducing the time and effort needed to determine the measurement was investigated by using half the number of replicated measurements for each calibration of the steel test tape. Table 5 lists the summary statistics for 20 repeated steel test tape calibration measurements using only two replicated measurements per interval. The difference in the statistics in table 5 compared to those in table 4 are small and within the resolution of the moving Vernier scale used for the measurements.

Table 6 lists the error contributed by the number of repeated measurements using the standard deviation from table 3 of $0.0011 \mathrm{ft}$. Each repeated measurement of the displacement between the test and reference tape is a sample of the actual displacement. The error or uncertainty, $u_{\text {sample size }}$, contributed by the number of repeated measurements or sample size (Eberhardt, 1990) can be estimated with a 95-percent confidence interval from $u_{\text {sample size }}=\frac{1.96 S}{\sqrt{n}}$, where $s$ is the standard deviation of the population, and $n$ is the number of samples or repeated measurements. In order to achieve a sampling error of the same size as the calibration device resolution of $0.0005 \mathrm{ft}$, 20 repeated measurements would be needed. However, two repeated measurements have only a slightly larger error than four repeated measurements, $0.0016 \mathrm{ft}$ versus $0.0011 \mathrm{ft}$. Both measurements are within the 0.0033 -ft goal and closely match the estimated expanded combined uncertainty estimated in the previous section. Because the calculation uses data for a steel test tape, the results may not be applicable to an electric tape. 
Table 3. Summary statistics of measured displacement between test tape and reference tape over 100-foot intervals for all individual interval measurements. Positive displacements are for tapes that measure long, and negative displacements are for tapes that measure short.

\begin{tabular}{|c|c|c|c|c|}
\hline $\begin{array}{c}\text { Number of interval } \\
\text { measurements }\end{array}$ & $\begin{array}{c}\text { Average } \\
\text { in } \mathrm{ft} \\
\end{array}$ & $\begin{array}{c}\text { Standard Deviation } \\
\text { in } \mathrm{ft}\end{array}$ & $\begin{array}{l}\text { Maximum } \\
\text { in } \mathrm{ft}\end{array}$ & $\begin{array}{c}\text { Minimum } \\
\text { in } \mathrm{ft}\end{array}$ \\
\hline 120 & -0.0007 & 0.0011 & 0.0020 & -0.0025 \\
\hline
\end{tabular}

Table 4. Summary statistics of 10 replicated steel tape calibrations using four repeated measurements to determine the average displacement with reference tape in feet over 100-foot intervals. Positive displacements are for tapes that measure long, and negative displacements are for tapes that measure short.

\begin{tabular}{|c|c|c|c|c|c|c|}
\hline $\begin{array}{c}\text { Tape interval } \\
\text { in } \mathrm{ft}\end{array}$ & $\begin{array}{c}\text { Number of } \\
\text { calibrations }\end{array}$ & $\begin{array}{c}\text { Average } \\
\text { in } \mathrm{ft}\end{array}$ & $\begin{array}{c}\text { Standard } \\
\text { deviation in } \mathrm{ft}\end{array}$ & $\begin{array}{c}\text { Maximum } \\
\text { in } \mathrm{ft}\end{array}$ & $\begin{array}{l}\text { Minimum } \\
\text { in } \mathrm{ft}\end{array}$ & $\begin{array}{c}\text { Standard erro } \\
\text { in } \mathrm{ft}\end{array}$ \\
\hline $0-100$ & 10 & 0.0002 & 0.0009 & 0.0014 & -0.0009 & 0.0003 \\
\hline $100-200$ & 10 & -0.0011 & 0.0008 & 0.0009 & -0.0020 & 0.0003 \\
\hline $200-300$ & 10 & -0.0013 & 0.0002 & -0.0009 & -0.0015 & 0.0001 \\
\hline All intervals & 30 & -0.0007 & 0.0010 & 0.0014 & -0.0020 & 0.0003 \\
\hline
\end{tabular}

Table 5. Summary statistics of 20 replicated steel tape calibrations using two repeated measurements to determine the average displacement with reference tape in feet $(\mathrm{ft}$ ) over $100-\mathrm{ft}$ intervals. Positive displacements are for tapes that measure long, and negative displacements are for tapes that measure short.

\begin{tabular}{ccccccc} 
[ft, feet] & Tape interval \\
in ft & $\begin{array}{c}\text { Number of } \\
\text { calibrations }\end{array}$ & $\begin{array}{c}\text { Average } \\
\text { in ft }\end{array}$ & $\begin{array}{c}\text { Standard } \\
\text { deviation in ft }\end{array}$ & $\begin{array}{c}\text { Maximum } \\
\text { in ft }\end{array}$ & $\begin{array}{c}\text { Minimum } \\
\text { in ft }\end{array}$ & $\begin{array}{c}\text { Standard error } \\
\text { in ft }\end{array}$ \\
\hline $0-100$ & 20 & 0.0003 & 0.0010 & 0.0018 & -0.0010 & 0.0002 \\
$100-200$ & 20 & -0.0023 & 0.0009 & 0.0013 & -0.0025 & 0.0002 \\
$200-300$ & 20 & -0.0025 & 0.0004 & -0.0005 & -0.0018 & 0.0001 \\
All intervals & 60 & -0.0007 & 0.0010 & 0.0018 & -0.0025 & 0.0001 \\
\hline
\end{tabular}

Table 6. Effect of sample size on interval-displacement measurement accuracy using a measurement standard deviation of 0.0011 foot.

\begin{tabular}{|c|c|}
\hline $\begin{array}{c}\text { Number of } \\
\text { repeated } \\
\text { measurements }\end{array}$ & $\begin{array}{l}\text { Error } \\
\text { in } \mathrm{ft}\end{array}$ \\
\hline 2 & 0.0016 \\
\hline 4 & 0.0011 \\
\hline 20 & 0.0005 \\
\hline
\end{tabular}




\section{Accuracy Testing of In-Service Groundwater-Level Tapes}

Accuracy of USGS in-service steel and electric groundwater-level tapes was tested by calibrating a sample of tapes from various USGS WSCs. A total of 29 in-service groundwater-level tapes were tested for compliance with the expected accuracy of $\pm 0.01 \mathrm{ft}$ per $100 \mathrm{ft}$. The expected accuracy is actually plotted in all figures as $\pm 0.0144 \mathrm{ft}$ to account for the rounding errors and the limitations imposed by recording water-level measurements to two significant figures. The previously described calibration method was conducted on the tapes indoors at the HIF Hydraulic Laboratory using the CD2 calibration device. Test results were also used to assess the repeatability of the test method for steel and electric tapes. The results for new and in-service electric tapes and for steel and electric in-service tapes were compared.

\section{In-Service Steel Tapes}

Fifteen in-service steel tapes, three each from WSCs in Arizona, Arkansas, New Jersey, Tennessee, and Pacific Islands, were calibrated. All tested in-service steel tapes are made by Lufkin. Selected information for the in-service steel tapes is listed in table 7. Overall, the sample of in-service steel tapes was legible and in good condition. Tape age did not seem to affect condition. Some of the in-service tapes were missing the first few feet of tape.

The total number of individual interval measurements was 264. Summary statistics for the individual interval measurements are listed in table 8 . Table 9 lists summary statistics for the calibration tests for the 15 tapes. Average measured interval displacements were similar, regardless of a measured interval, and ranged from $-0.0024 \mathrm{ft}$ ( 300 - to $400-\mathrm{ft}$ interval) to $-0.0088 \mathrm{ft}$ (500- to $1,000-\mathrm{ft}$ interval) and averaged $-0.0048 \mathrm{ft}$. Missing the first few feet of tape did not appear to greatly affect the accuracy of the tape. The standard deviation for all in-service steel tape measurements, a measure of the length variability in the 100 - $\mathrm{ft}$ intervals, was $0.0048 \mathrm{ft}$ (table 9). A box plot of the calibration data for the in-service steel tapes, plotted with the expected accuracy of $\pm 0.01 \mathrm{ft}$, is shown in figure 5 . Figures 6,7 , and 8 , respectively, show the cumulative displacement between the sample tapes and the reference tape for short $(<300-\mathrm{ft}), 300-\mathrm{ft}$, and long ( $>300-\mathrm{ft}$ ) tapes. All in-service tapes were within the expected accuracy of $\pm 0.01 \mathrm{ft}$.

The standard deviations computed from the individual interval measurements for each in-service tape were pooled by averaging those standard deviations. The pooling removed the effect of different length sections from the standard deviation so that the random uncertainty for the calibration method using CD2 could be estimated. The pooled standard deviation for the in-service steel tapes was $0.0005 \mathrm{ft}$ for $51100-\mathrm{ft}$ segments.
Data for a NIST calibration of the 1000-ft in-service steel tape became available after the study work was completed. A simple comparison of the NIST calibration with the study calibration for this tape found a testing bias of $-0.007 \mathrm{ft}$ per $100-\mathrm{ft}$ interval. This bias may be limited to this tape calibration. The testing bias can be estimated from the data by assuming that the group of the in-service steel is unbiased and any nonzero median is due to a testing bias. Estimating the testing bias from the median of the data for the 100-, 200-, 300-, 400-, and 500 -ft-tape intervals, gives an average bias of $-0.004 \mathrm{ft}$ per 100 -ft interval. Both bias estimation methods indicate that the calibration method is adequate for calibrating tapes to $\pm 0.01 \mathrm{ft}$, but could be improved.

\section{In-Service Electric Tapes}

Fourteen in-service electric tapes, two each from the Arkansas, Nebraska, Nevada, North Carolina, Ohio, Pennsylvania, and South Carolina WSCs, were calibrated. Table 10 compares the number of electric-tape makes and models used by WSCs based on OGW survey results (Rod Sheets, U.S. Geological Survey, Office of Groundwater, written commun., 2011) with the study sample of in-service electric-tape makes. The sample of electric tapes from the WSCs approximately matches the proportions of makes and models used by WSCs. Four models, Heron, GeoTech (Keck), RST, and In-Situ, are overrepresented in the sample. The Waterline model, used by 20 percent of the WSCs, was not included in the sample. Table 11 lists selected information for the submitted in-service electric tapes. The sample of in-service electric tapes had signs of wear. The plastic jacket of most of the electric tapes showed signs of abrasion and wear that made the markings hard to read over the first few feet. One electric tape was submitted with a nonfunctional water-level indicator.

The electric-tape calibration was a two-step process. The distance between the 1-ft mark and the probe activation level (probe offset) was calibrated using the method described by Jelinski and others (2015). The electric-tape length between the 1-ft mark and the end of the electric tape was calibrated using the calibration method and the CD2 device (CD2) described in this report. The combined measured probe offset and measured tape correction gave the tape correction.

The probe-offset calibration used a device that consisted of a frame with three sliders. One slider held the tape at the 1 - $\mathrm{ft}$ mark and the other sliders held hook gauges. A cup filled with water, having a specific conductance of 1,000 microsiemens per centimeter $(\mu \mathrm{S} / \mathrm{cm})$ at 25 degrees Celsius, was placed below the tape probe and hook gauge. The tape probe was lowered into the water until it indicated contact with the water surface. A hook gauge was used to measure that distance from the 1-ft mark to a water surface. A detailed description of the probe-offset calibration device and procedure is given in Jelinski and others (2015).

Table 12 lists summary statistics for all the individual interval-displacement measurements and for the probe-offset 
Table 7. Information for in-service steel tapes manufactured by Lufkin and calibrated by proposed procedure and device.

[WSC, U.S. Geological Survey Water Science Center; ID, identifier; ft, feet]

\begin{tabular}{|c|c|c|c|c|c|c|c|}
\hline WSC & ID & Model $^{1}$ & Condition $^{2}$ & Age $^{1}$ & Usage $^{3}$ & $\begin{array}{l}\text { Original length } \\
\text { in } \mathrm{ft}\end{array}$ & $\begin{array}{l}\text { Current length }{ }^{1} \\
\text { in } \mathrm{ft}\end{array}$ \\
\hline Arizona & 001 & 030402 & Good & 10 years & Calibration only & 500 & 500 \\
\hline Arizona & 011 & Unknown & Excellent & 8 years & $\begin{array}{c}50 \text { wells } \sim 17 \\
\text { trips/year }\end{array}$ & 200 & 200 \\
\hline Arizona & 012 & Unknown & Good & 3 years & $\begin{array}{c}50 \text { wells } \sim 17 \\
\text { trips/year }\end{array}$ & 300 & 300 \\
\hline Arkansas & F-05 & Unknown & Good & $>10$ years & 50/year & 500 & 493 \\
\hline Arkansas & E-04 & 2967058 & Fair, some rust & $>10$ years & 50-100/year & 300 & 268 \\
\hline Arkansas & E-05 & Unknown & $\begin{array}{l}\text { Good, } \\
\text { minor rust }\end{array}$ & $>10$ years & 50-100/year & 300 & 271 \\
\hline New Jersey & NJ-001 & 24103 & $\begin{array}{l}\text { Good, many } \\
\text { small kinks }\end{array}$ & “Older” & $\begin{array}{l}\text { Regular use, } \\
\text { toxics }\end{array}$ & 100 & 99 \\
\hline New Jersey & NJ-002 & 180165 & $\begin{array}{l}\text { Good, } \\
\text { moderate rust }\end{array}$ & "Newer" & $\begin{array}{l}\text { Heavy use, } \\
\text { GW network }\end{array}$ & 200 & 200 \\
\hline New Jersey & NJ-003 & Unknown & $\begin{array}{l}\text { Good, } \\
\text { minor rust }\end{array}$ & "Newer" & 10-15/year & 300 & 300 \\
\hline Tennessee & Logger \#1 & 240910 & $\begin{array}{l}\text { Well used, } \\
\text { moderate rust }\end{array}$ & $>30$ years & 10-20/year & 200 & 90 \\
\hline Tennessee & Logger \#2 & 180165 & $\begin{array}{l}\text { Good, } \\
\text { some rust }\end{array}$ & $>30$ years & 10-20/year & 200 & 200 \\
\hline Tennessee & $\begin{array}{c}\text { TN WSC } \\
500\end{array}$ & Unknown & $\begin{array}{l}\text { Well used, } \\
\text { moderate rust }\end{array}$ & $>30$ years & $\begin{array}{l}\text { Light use, } \\
\text { few/year }\end{array}$ & 500 & 471 \\
\hline Pacific Island & $\begin{array}{c}\text { PIWSC } \\
\text { Reference }\end{array}$ & Unknown & Good & 10 years & $\begin{array}{l}\text { Light use/ } \\
\text { reference tape }\end{array}$ & 1000 & 1000 \\
\hline Pacific Island & ST07-04 & 030402 & Good & 5 years & $\begin{array}{l}\text { Never, } \\
\text { calibration } \\
\text { problem }\end{array}$ & 500 & 500 \\
\hline Pacific Island & OAST-10 & 18065 & Good & Unknown & Moderate use & 100 & 100 \\
\hline
\end{tabular}

${ }^{1}$ Read off tape. Length is approximate, to first whole foot mark.

${ }^{2}$ Condition estimate based on appearance. Most issues occurred within first $50 \mathrm{ft}$ of tape.

${ }^{3}$ Information provided by individual U.S. Geological Survey Water Science Center.

Table 8. Summary statistics of measured displacement between in-service steel tape and reference tape over 100-foot intervals for all individual interval measurements. Positive displacements are for tapes that measure long, and negative displacements are for tapes that measure short.

[ft, feet]

\begin{tabular}{|c|c|c|c|c|}
\hline $\begin{array}{c}\text { Number of interval } \\
\text { measurements }\end{array}$ & $\begin{array}{c}\text { Average } \\
\text { in } \mathrm{ft}\end{array}$ & $\begin{array}{c}\text { Standard Deviation } \\
\text { in } \mathrm{ft}\end{array}$ & $\begin{array}{c}\text { Maximum } \\
\text { in } \mathrm{ft}\end{array}$ & $\begin{array}{c}\text { Minimum } \\
\text { in ft }\end{array}$ \\
\hline 264 & -0.0049 & 0.0048 & 0.01082 & -0.0154 \\
\hline
\end{tabular}




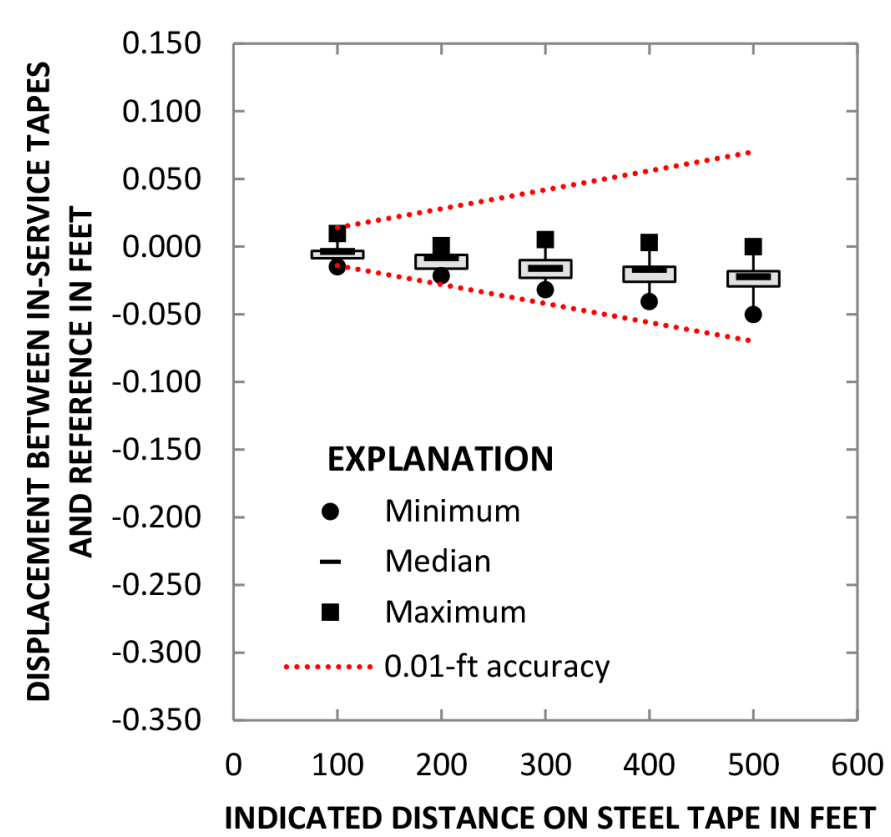

Figure 5. The cumulative measured displacement between 15 U.S. Geological Survey Water Science Center in-service steel test tapes and the steel reference tape plotted with an expected accuracy of 0.01 foot $(\mathrm{ft}$ ) per 100-ft length. The test tapes were tested at a reference tension of 10 pounds and over each $100-\mathrm{ft}$ graduated interval.

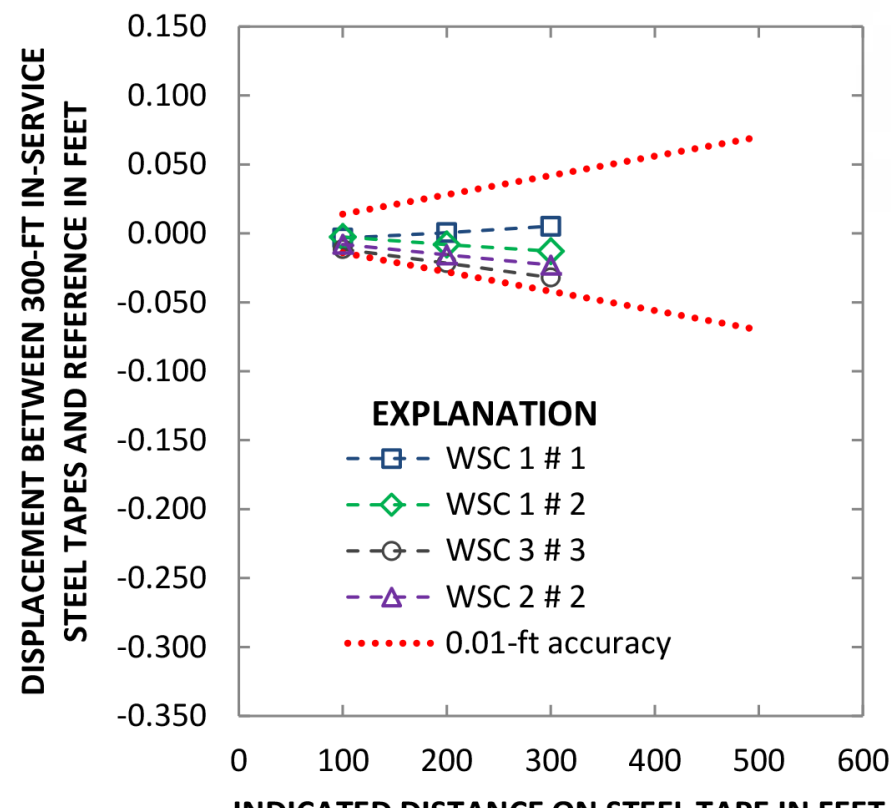
INDICATED DISTANCE ON STEEL TAPE IN FEET

Figure 7. The cumulative measured displacement for 100-foot ( $\mathrm{ft}$ ) graduation intervals between in-service 300 -ft steel test tapes and the steel reference tape. The tapes were tested at a reference tension of 10 pounds and are plotted with the expected accuracy of $0.01 \mathrm{ft}$ per $100-\mathrm{ft}$ length.

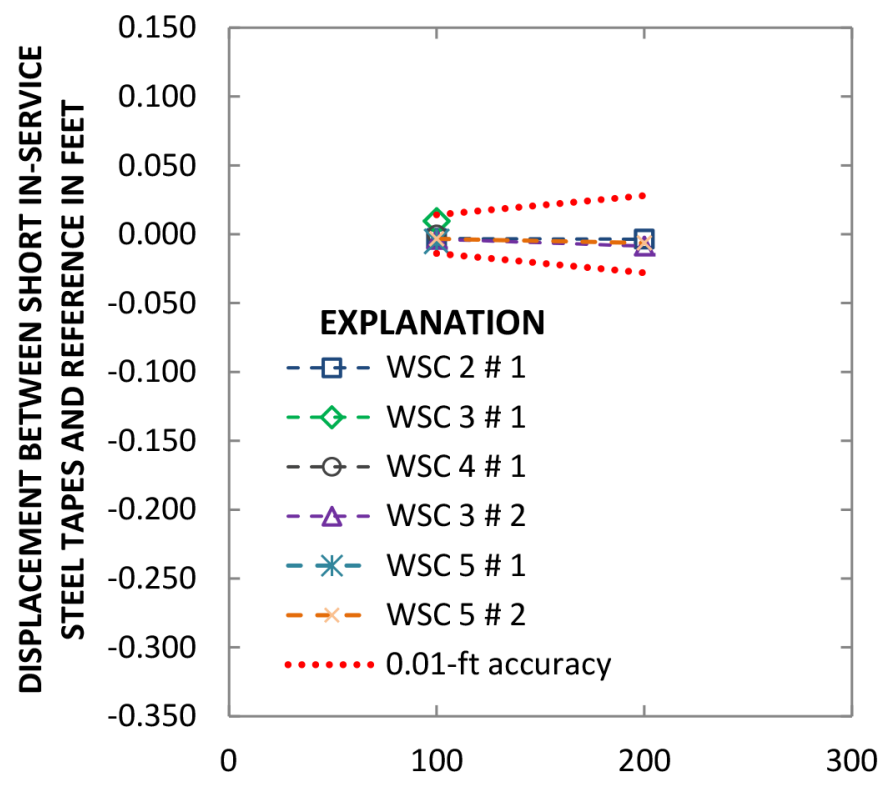

INDICATED DISTANCE ON STEEL TAPE IN FEET

Figure 6. The cumulative measured displacement for 100-foot (ft) graduation intervals between in-service steel test tapes less than $300 \mathrm{ft}$ in length and the steel reference tape. The tapes were tested at a reference tension of 10 pounds and are plotted with the expected accuracy of $0.01 \mathrm{ft}$ per $100-\mathrm{ft}$ length.

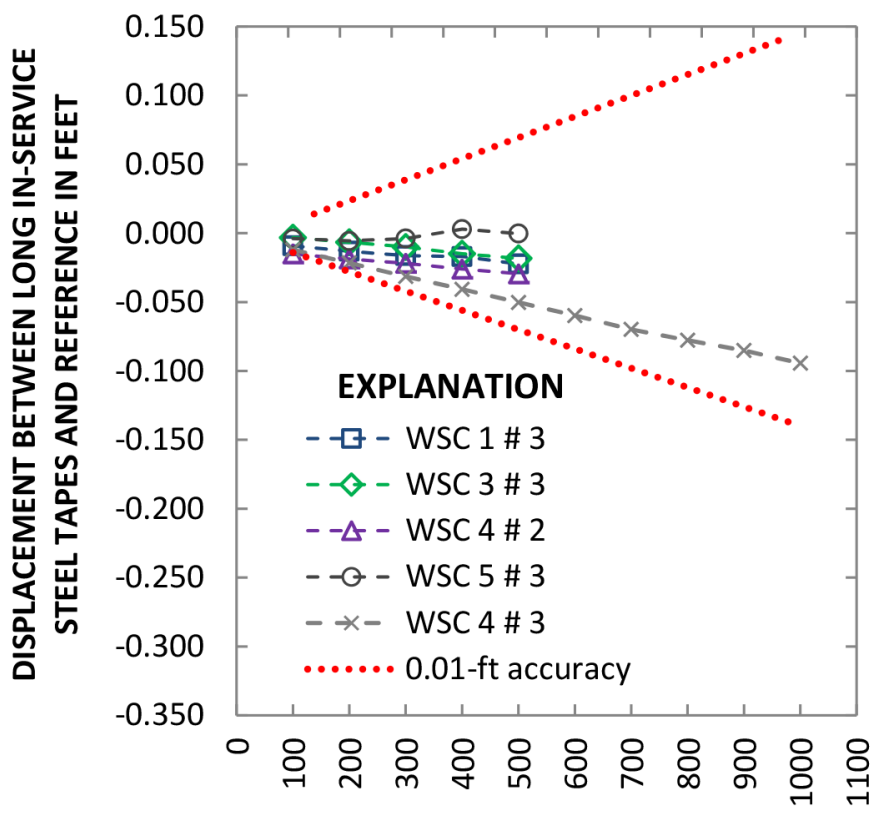

INDICATED DISTANCE ON STEEL TAPE IN FEET

Figure 8. The cumulative measured displacement for 100-foot (ft) graduation intervals between in-service steel test tapes greater than $300 \mathrm{ft}$ in length and the steel reference tape. The tapes were tested at a reference tension of 10 pounds and are plotted with the expected accuracy of $0.01 \mathrm{ft}$ per $100-\mathrm{ft}$ length. 
Table 9. Summary statistics for 15 in-service steel tapes, using four repeated measurements to determine the displacement with the reference tape over a 100-ft interval. Positive displacements are for tapes that measure long, and negative displacements are for tapes that measure short.

\begin{tabular}{cccccccc} 
[ft, feet] & \multicolumn{1}{c}{ Interval } \\
$\begin{array}{c}\text { Tape Interval } \\
\text { in ft }\end{array}$ & $\begin{array}{c}\text { Number } \\
\text { of tapes }\end{array}$ & $\begin{array}{c}\text { Average } \\
\text { in ft }\end{array}$ & $\begin{array}{c}\text { Standard } \\
\text { deviation in ft }\end{array}$ & $\begin{array}{c}\text { Maximum } \\
\text { in ft }\end{array}$ & $\begin{array}{c}\text { Minimum } \\
\text { in ft }\end{array}$ & $\begin{array}{c}\text { Median } \\
\text { in ft }\end{array}$ \\
\hline $0-100$ & 14 & 14 & -0.0052 & 0.0059 & 0.0108 & -0.0154 & -0.0045 \\
$100-200$ & 13 & 13 & -0.0043 & 0.0037 & 0.0041 & -0.0109 & -0.0039 \\
$200-300$ & 9 & 9 & -0.0040 & 0.0047 & -0.0051 & -0.0109 & -0.0034 \\
$300-400$ & 5 & 5 & -0.0024 & 0.0055 & 0.0071 & -0.0094 & -0.0039 \\
$400-500$ & 5 & 5 & -0.0050 & 0.0025 & -0.0029 & -0.0099 & -0.0034 \\
$500-1,000$ & 1 & 5 & -0.0088 & 0.0011 & -0.0074 & -0.0109 & -0.0089 \\
All intervals & 15 & 51 & -0.0048 & 0.0048 & 0.0108 & -0.0154 & -0.0044 \\
\hline
\end{tabular}

Table 10. Based on the U.S. Geological Survey Office of Groundwater survey, comparison of quantity and makes of in-service electric groundwater-level tapes with the study numbers and makes of in-service electric tapes.

\begin{tabular}{lcccc} 
[\%, percent; Durham Geo Slope Indicator, DGSI] & & \\
\hline \multicolumn{1}{c}{ Make } & $\begin{array}{c}\text { Total } \\
\text { in service }\end{array}$ & $\begin{array}{c}\text { Percentage of } \\
\text { in-service } \\
\text { tapes }\end{array}$ & $\begin{array}{c}\text { Number } \\
\text { in study }\end{array}$ & $\begin{array}{c}\text { Percent } \\
\text { in study }\end{array}$ \\
\hline Solinst & 286 & $47 \%$ & 5 & $43 \%$ \\
DGSI & 135 & $22 \%$ & 4 & $29 \%$ \\
Heron & 21 & $3.5 \%$ & 1 & $7.1 \%$ \\
Waterline & 103 & $17 \%$ & 0 & $0 \%$ \\
RST & 14 & $2.3 \%$ & 1 & $7.1 \%$ \\
Instruments & & & & \\
In-Situ & 13 & $2.1 \%$ & 1 & $7.1 \%$ \\
GeoTech, & 34 & $5.6 \%$ & 1 & $7.1 \%$ \\
(Keck) & & & & \\
\hline
\end{tabular}

measurements. Eleven of the 14 probes were tested. One tape, the Solinst Model 102, failed calibration of the probe offset because of an electrical fault in the probe. The average probe offset was $0.0026 \mathrm{ft}$ and ranged from 0.0147 to $-0.0102 \mathrm{ft}$. Probe offsets are usually small and not a large source of electric-tape error. For a field calibration, the probe-offset calibration may not be necessary unless the probe has been pulled from its original position on the tape. Probe errors are generally much less than the tape errors, especially on longer tapes, and should not change during the life of the tape, as long as the probe is not damaged and the electrodes are kept clean. However, probes should be checked for function and offsets should be measured prior to first use of the tape.

The reference tape and CD2 were used to calibrate the in-service electric tapes. The total number of individual interval-displacement measurements was 168 (table 12). The standard deviation for all in-service electric-tape measurements was $0.0433 \mathrm{ft}$ and is a measure of the length variability in the 100-ft intervals for the 14 electric tapes. Differences in materials and construction used by the various electrictape models, as well as variation in the tape lengths over the intervals, increased the standard deviation when compared to the steel tapes. Table 13 lists statistics for the calibrations of the 14 in-service electric tapes for each measured interval. The average measured interval displacement for the electric tapes ranged from 0.0190 (500- to 1,000 - $\mathrm{ft}$ intervals) to $-0.0077 \mathrm{ft}$ (200- to $300-\mathrm{ft}$ intervals) and averaged $-0.0274 \mathrm{ft}$. Table 14 lists statistics for the measured interval displacement of the 14 in-service electric tapes for each model over the 0 - to $100-\mathrm{ft}$ interval and for the average of all the measured intervals. The combined average for all the intervals ranged from 0.0349 $\mathrm{ft}$ for six Solinst 101 tapes to $-0.0660 \mathrm{ft}$ for one RST model 3001 tape. The average interval displacement, or the average interval accuracy, measured for the in-service electric tapes exceeded $\pm 0.01 \mathrm{ft}$. The range of average interval accuracy (average displacement) from -0.0660 to $0.0349 \mathrm{ft}$ is similar to the accuracy range of -0.0453 to $0.0376 \mathrm{ft}$ for new electric tapes measured by Jelinski and others (2015) and fits within the accuracy range of 0.02 to $0.1 \mathrm{ft}$ for electric tapes mentioned by Holmes and others (2001).

The standard deviations computed from the individual interval measurements for each in-service electric tape were pooled by averaging those standard deviations. The standard deviations were pooled to estimate the measurement repeatability (or random uncertainty) for the method used to check the tapes. The pooled standard deviation for the in-service electric tapes was $0.0006 \mathrm{ft}$ for 42100 -ft intervals. In general, tape stretch and friction between the concrete floor and the electric tapes made it more difficult to evenly apply tension to electric tapes than to steel tapes. Tapes with a flat steel strength member were easier to evenly tension than those with round coaxial cable members. However, electric-tape calibrations were about as repeatable as those for steel tapes and the models using coaxial cable (Durham Geo Water Slope Indicator) were as repeatable as models using a flat tape. The pooled standard deviation for Durham Geo Water Slope Indicator (DGSI) tapes was $0.0007 \mathrm{ft}$ for $8100-\mathrm{ft}$ segments and for models using a flat tape, the standard deviation was $0.0006 \mathrm{ft}$ for 34 100-ft segments. 
Table 11. Information for the sample of in-service electric tapes used to check accuracy of electric groundwater-level tapes used by the U.S. Geological Survey (USGS).

[WSC, USGS Water Science Center; ID, identifier; ft, feet; DGSI, Durham Geo Slope Indicator]

\begin{tabular}{|c|c|c|c|c|c|c|c|}
\hline WSC & ID & Make & Model & Condition ${ }^{1}$ & $\mathrm{Age}^{2}$ & Usage $^{2}$ & Length in $\mathrm{ft}$ \\
\hline Arkansas & B-04 & DGSI & $\begin{array}{c}\text { Water Level } \\
\text { Indicator }\end{array}$ & Good & 4 years & 125-500/year & 300 \\
\hline Arkansas & $\mathrm{K}-05$ & Solinst & Model 102 & Non-functional ${ }^{3}$ & 2 years & 400/year & 300 \\
\hline Nebraska & SN: 33890 & Solinst & Model 101 & Very good & Unknown & Unknown & 200 \\
\hline Nebraska & Beep & Solinst & Model 101 & Well used & 10 years & 300/year & 300 \\
\hline Nevada & ET-12 & Solinst & Model 101 & Good & Unknown & Unknown & 1,000 \\
\hline Nevada & WL 3247 & RST & Model 3001 & Good & Unknown & Unknown & 500 \\
\hline North Carolina & CFO-008 & DGSI & $\begin{array}{l}\text { Water Level } \\
\text { Indicator }\end{array}$ & Good & $>2$ years & None recently & 100 \\
\hline North Carolina & KECK 2045 & Geotech Keck & $\begin{array}{l}\text { Water Level } \\
\text { Meter }\end{array}$ & Fair & 6 years & 60/year & 100 \\
\hline Ohio & SN: 15279 & DGSI & $\begin{array}{l}\text { Water Level } \\
\text { Indicator }\end{array}$ & Good & 6 years & 150/year & 150 \\
\hline Ohio & SN: 27330 & Solinst & Model 101 & Good & 6 years & $350 /$ year & 200 \\
\hline Pennsylvania & EX-E01 & DGSI & $\begin{array}{c}\text { Water Level } \\
\text { Indicator }\end{array}$ & Good & $>8$ years & $5-25 /$ year & 150 \\
\hline Pennsylvania & NC-E03 & Solinst & Model 101 & Good & Unknown & Unknown & 200 \\
\hline South Carolina & SN: 19088 & Heron & dipper-T & Good & Unknown & Unknown & 300 \\
\hline South Carolina & SN: 25975 & In-Situ & Model 200 & Excellent & Unknown & Unknown & 300 \\
\hline
\end{tabular}

${ }^{1}$ Condition estimate based on appearance. Most wear occurred within first $50 \mathrm{ft}$ of tape.

${ }^{2}$ Information provided by individual WSC.

${ }^{3}$ Tape probe did not detect water. Tape length calibrated from 1-ft mark.

Table 12. Summary statistics of in-service electric-tape measurements, individual interval-displacement measurements, and probeoffset errors. Positive displacements are for tapes that measure long, and negative displacements are for tapes that measure short. [ft, feet]

\begin{tabular}{lcccccc}
\hline \multicolumn{1}{c}{ Measurement } & $\begin{array}{c}\text { Number of } \\
\text { units tested }\end{array}$ & $\begin{array}{c}\text { Number of } \\
\text { measurements }\end{array}$ & $\begin{array}{c}\text { Average } \\
\text { in ft }\end{array}$ & $\begin{array}{c}\text { Standard } \\
\text { deviation in ft }\end{array}$ & $\begin{array}{c}\text { Maximum } \\
\text { in ft }\end{array}$ & $\begin{array}{c}\text { Minimum } \\
\text { in ft }\end{array}$ \\
\hline Interval markings & 14 & 168 & -0.0274 & 0.0433 & 0.1136 & -0.1754 \\
Probe offset & 10 & 40 & 0.0026 & 0.0067 & 0.0147 & -0.0102 \\
\hline
\end{tabular}


Table 13. Summary statistics of in-service electric groundwater-level tape displacement measurements using four measurements for each 100-foot interval. Positive displacements are for tapes that measure long, and negative displacements are for tapes that measure short.

\begin{tabular}{|c|c|c|c|c|c|c|c|}
\hline $\begin{array}{c}\text { Tape interval } \\
\text { in } \mathrm{ft}\end{array}$ & $\begin{array}{l}\text { Number } \\
\text { of tapes }\end{array}$ & $\begin{array}{c}\text { Interval } \\
\text { count }\end{array}$ & $\begin{array}{c}\text { Average } \\
\text { in } \mathrm{ft}\end{array}$ & $\begin{array}{c}\text { Standard } \\
\text { deviation in } \mathrm{ft}\end{array}$ & $\begin{array}{l}\text { Maximum } \\
\text { in } \mathrm{ft}\end{array}$ & $\begin{array}{l}\text { Minimum } \\
\text { in } \mathrm{ft}\end{array}$ & $\begin{array}{c}\text { Median } \\
\text { in ft }\end{array}$ \\
\hline $0-100$ & 14 & 14 & -0.0534 & 0.0424 & 0.0067 & -0.1790 & -0.0527 \\
\hline $100-200$ & 12 & 12 & -0.0276 & 0.0242 & 0.0141 & -0.0709 & -0.0194 \\
\hline $200-300$ & 7 & 7 & -0.0077 & 0.0554 & 0.1136 & -0.0674 & -0.0109 \\
\hline $300-400$ & 2 & 2 & -0.0292 & 0.0336 & 0.0026 & -0.0614 & -0.0292 \\
\hline $500-1,000$ & 1 & 5 & 0.0190 & 0.0032 & 0.0231 & 0.0136 & 0.0193 \\
\hline $\begin{array}{c}\text { All } \\
\text { measurements }\end{array}$ & 14 & 42 & -0.0274 & 0.0433 & 0.1136 & -0.1754 & -0.0242 \\
\hline
\end{tabular}

Table 14. Summary statistics of in-service electric groundwater-level tape displacement measurements over 100-ft tape intervals by model. Positive displacements are for tapes that measure long, and negative displacements are for tapes that measure short.

\begin{tabular}{|c|c|c|c|c|c|}
\hline $\begin{array}{l}\text { Number } \\
\text { of tapes }\end{array}$ & $\begin{array}{l}0 \text {-100 interval } \\
\text { average in } \mathrm{ft}\end{array}$ & $\begin{array}{c}\text { Number of } \\
\text { measured segments }\end{array}$ & $\begin{array}{l}\text { Average for all } \\
\text { intervals in } \mathrm{ft}\end{array}$ & $\begin{array}{c}\text { Standard } \\
\text { deviation in } \mathrm{ft}\end{array}$ & $\begin{array}{c}\text { Average probe } \\
\text { offset in } \mathrm{ft}\end{array}$ \\
\hline 4 & -0.0732 & 8 & -0.0252 & 0.0776 & 0.0032 \\
\hline 5 & -0.0541 & 24 & -0.0264 & 0.0349 & 0.0002 \\
\hline 1 & -0.0131 & 3 & -0.0088 & 0.0058 & not work \\
\hline 1 & -0.0646 & 3 & -0.0602 & 0.0047 & 0.0060 \\
\hline 1 & -0.0324 & 3 & -0.0299 & 0.0027 & -0.0043 \\
\hline 1 & -0.0708 & 5 & -0.0660 & 0.0045 & unmeas. \\
\hline
\end{tabular}

\section{Comparison of In-Service with New Electric Tapes}

Calibration data from the in-service electric tapes are plotted in figure 9 with the calibration data for new electric tapes (Jelinski and others, 2015). The new electric-tape data shown in figure 9 include calibrations for each of the following: Solinst Model 101, DGSI, Geotech Keck Water Level Meter, Heron dipper-T, and In-Situ Model 200. Figures 10, 11,12 , and 13 are plots of the cumulative displacements for the new and in-service electric groundwater-level tapes with the reference tape. Figure 14 is a plot for the in-service Solinst 102 and figure 15 is a plot of in-service RST model 3001 for the cumulative difference between the electric tape and the reference tape. No comparison data for new tapes were available for these models.

Table 14 lists accuracy measurements for new and inservice electric tapes grouped by tape construction. The DGSI, Solinst models 101 and 102, and RST model 3001 tapes do not have a flat steel core. The other in-service tape models, Geotech Keck Water Level Meter, In-Situ Model 200, and Heron dipper-T, have a flat steel core. Figures 16 and 17 show the cumulative difference between new and in-service electric tapes with steel cores and those without them with the reference tape. The data show that the steel-cored tapes maintain their length and accuracy fairly well during use, especially when compared to tapes without a steel core. The tapes without steel cores may require a much more rigorous calibration plan to maintain accurate measurements. 

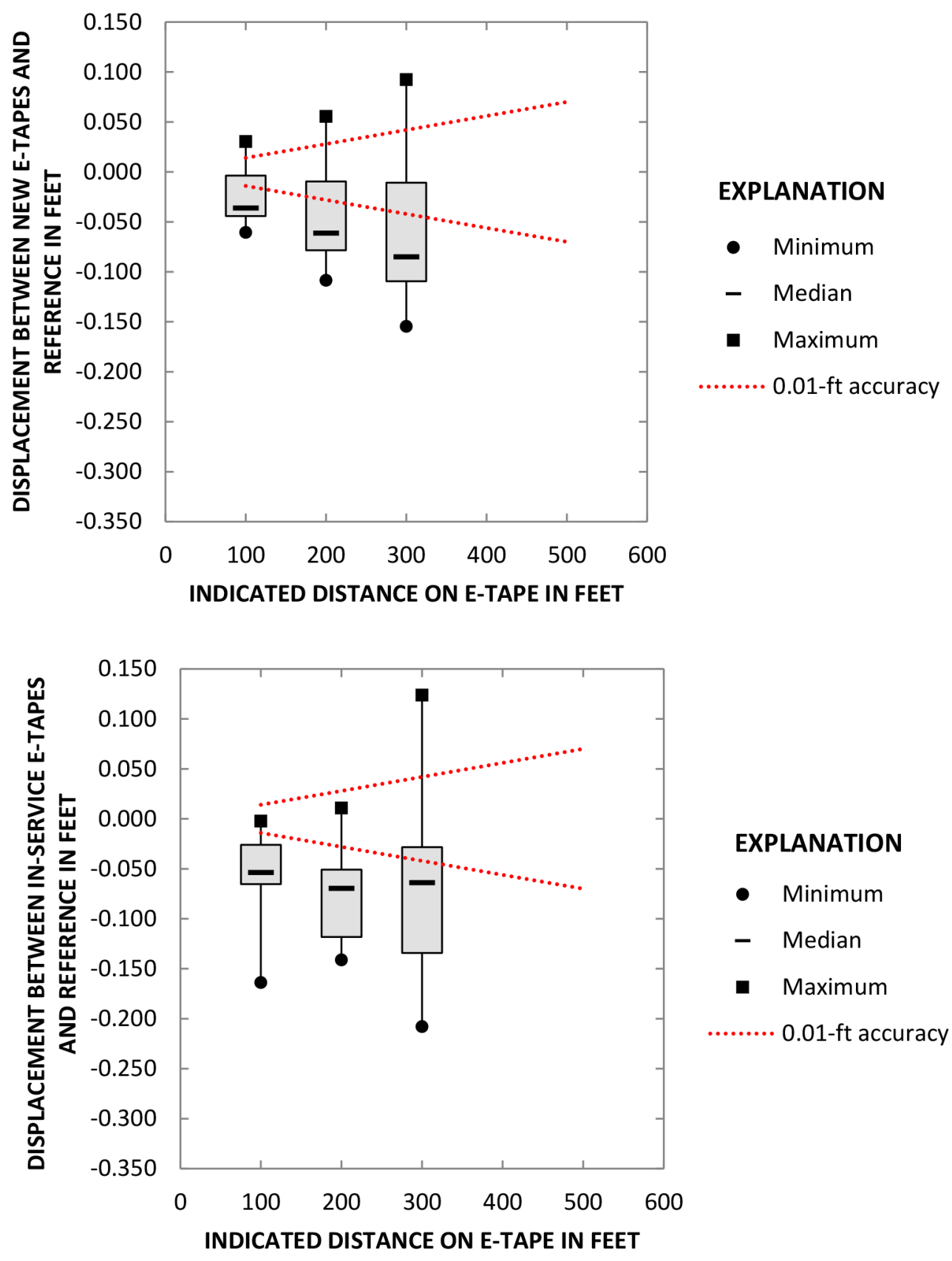

Figure 9. For new (top chart) and for 14 U.S. Geological Survey Water Science Center in-service electric test tapes (E-TAPES) (bottom chart), the cumulative measured displacement between E-TAPES and the steel reference tape plotted with an expected accuracy of 0.01 foot (ft) per 100-ft length. The E-TAPES were tested with in-use tension. 

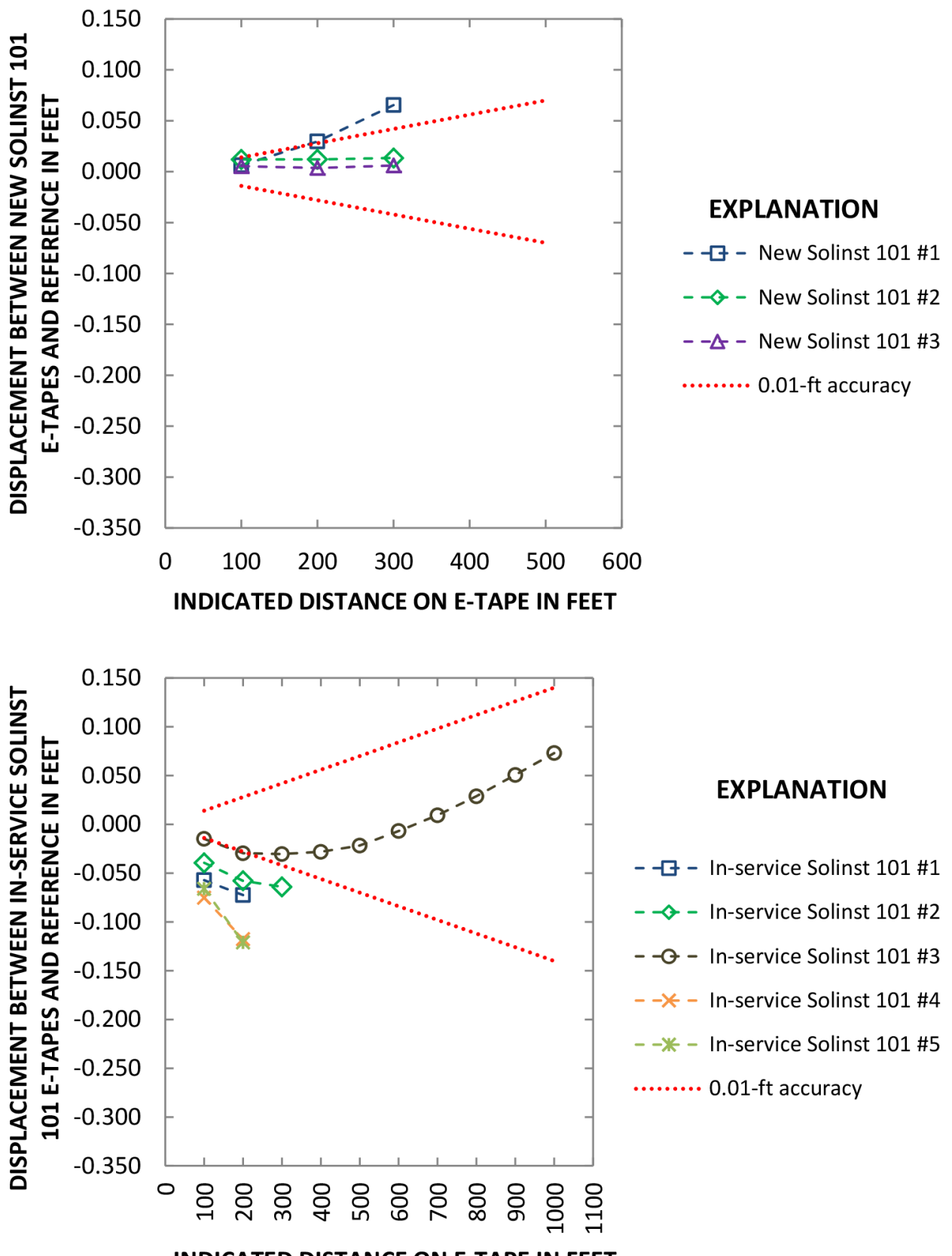

Figure 10. The cumulative measured displacement between Solinst model 101 electric test tapes (E-TAPES) and the steel reference tape plotted with an expected accuracy of 0.01 foot (ft) per 100-ft length for new (top chart) and for U.S. Geological Survey Water Science Center in-service E-TAPES (bottom chart). The E-TAPES were tested with in-use tension. 


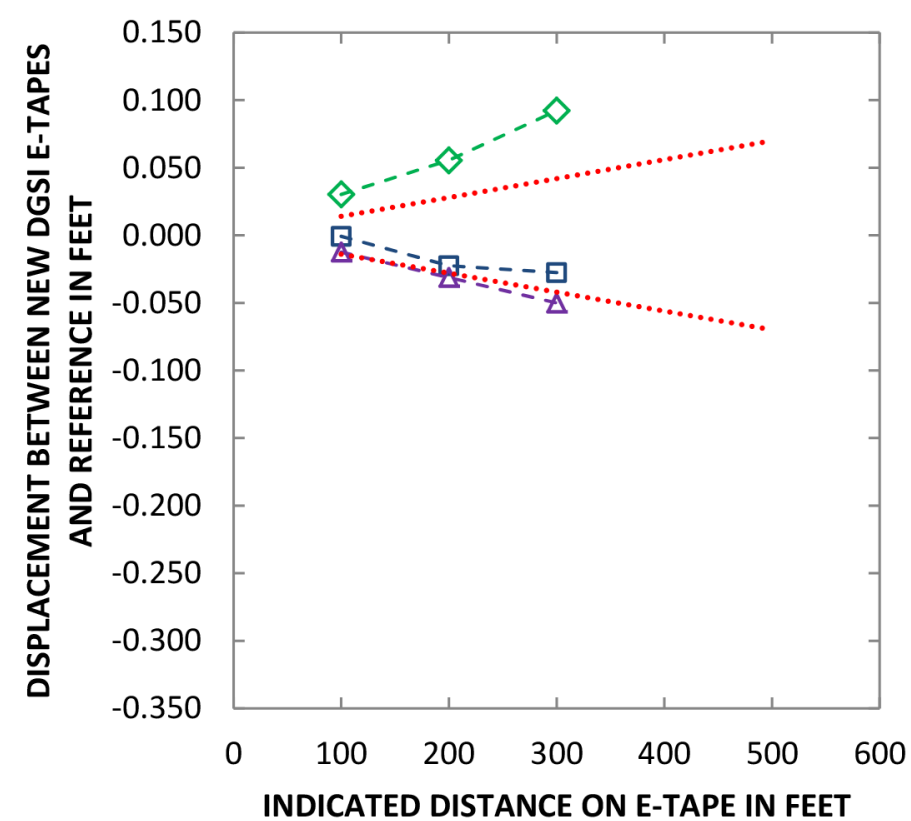

\section{EXPLANATION}

- $\square-$ New DGSI \#1

$-\prec-$ New DGSI \#2

$--\Delta-$ New DGSI \#3

.........0.01-ft accuracy

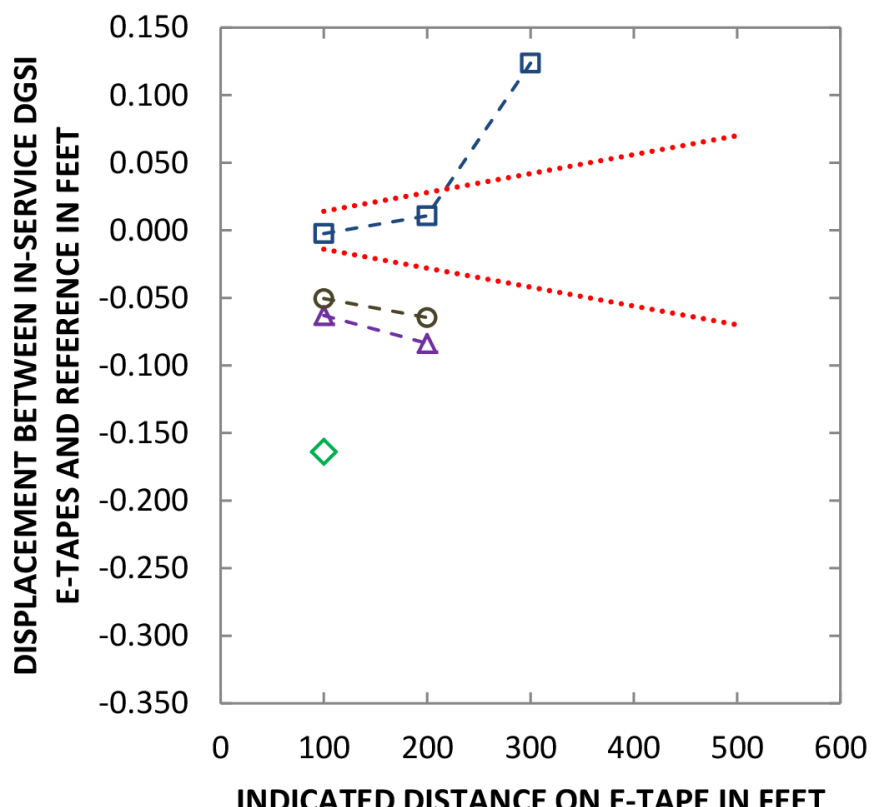

\section{EXPLANATION}

- - - - In-service DGSI \#1

- $\diamond$ - In-service DGSI \#2

- $-\Delta-$ In-service DGSI \#3

- $\bigcirc$ - In-service DGSI \#4 0.01-ft accuracy

Figure 11. The cumulative measured displacement between Slope Indicator electric test tapes (E-TAPES) and the steel reference tape plotted with an expected accuracy of 0.01 foot (ft) per 100-ft length for new (top chart) and for U.S. Geological Survey Water Science Center in-service E-TAPES (bottom chart). The E-TAPES were tested with in-use tension. 


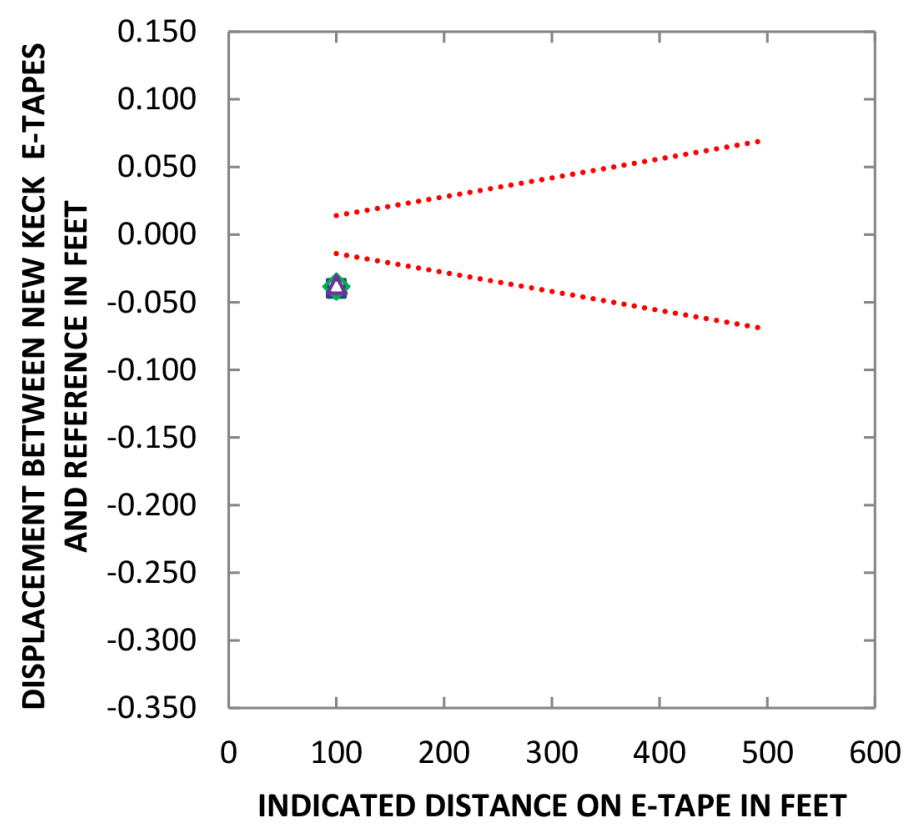

\section{EXPLANATION}

- $\square$ - New Keck \#1

$--\infty$ - New Keck \#2

- $-\Delta-$ New Keck \#3

....... 0.01-ft accuracy

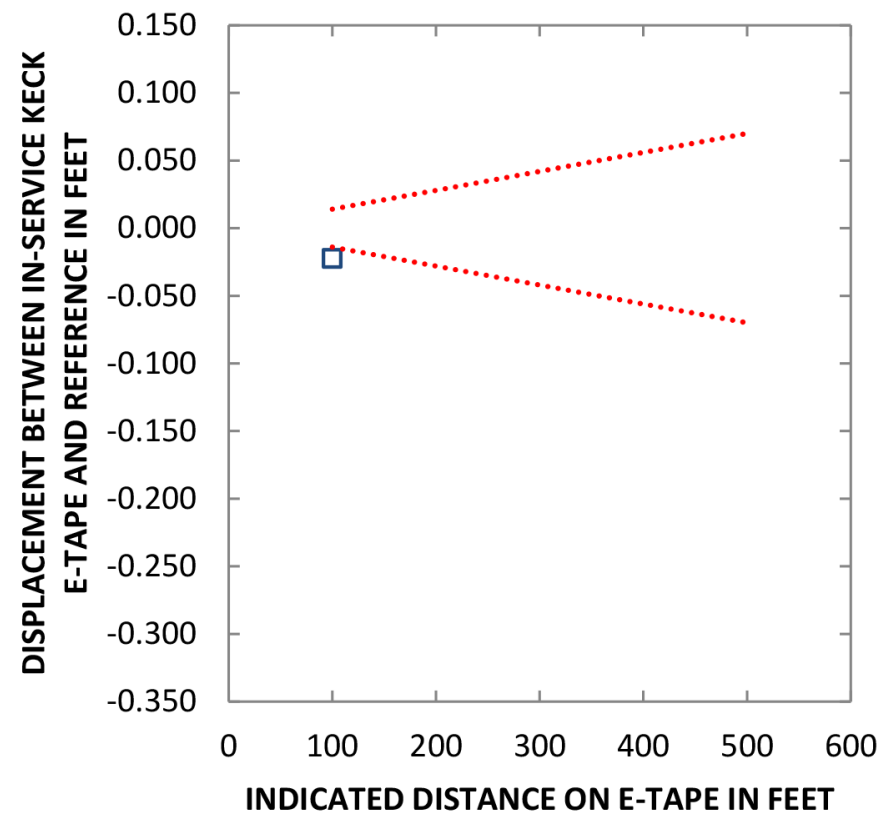

\section{EXPLANATION}

- - $\square$ - In-service Keck \#1

$0.01-\mathrm{ft}$ accuracy

Figure 12. The cumulative measured displacement between Keck electric test tapes (E-TAPES) and the steel reference tape plotted with an expected accuracy of 0.01 foot (ft) per 100-ft length for new (top chart) and for U.S. Geological Survey Water Science Center in-service E-TAPES (bottom chart). The E-TAPES were tested with in-use tension. 


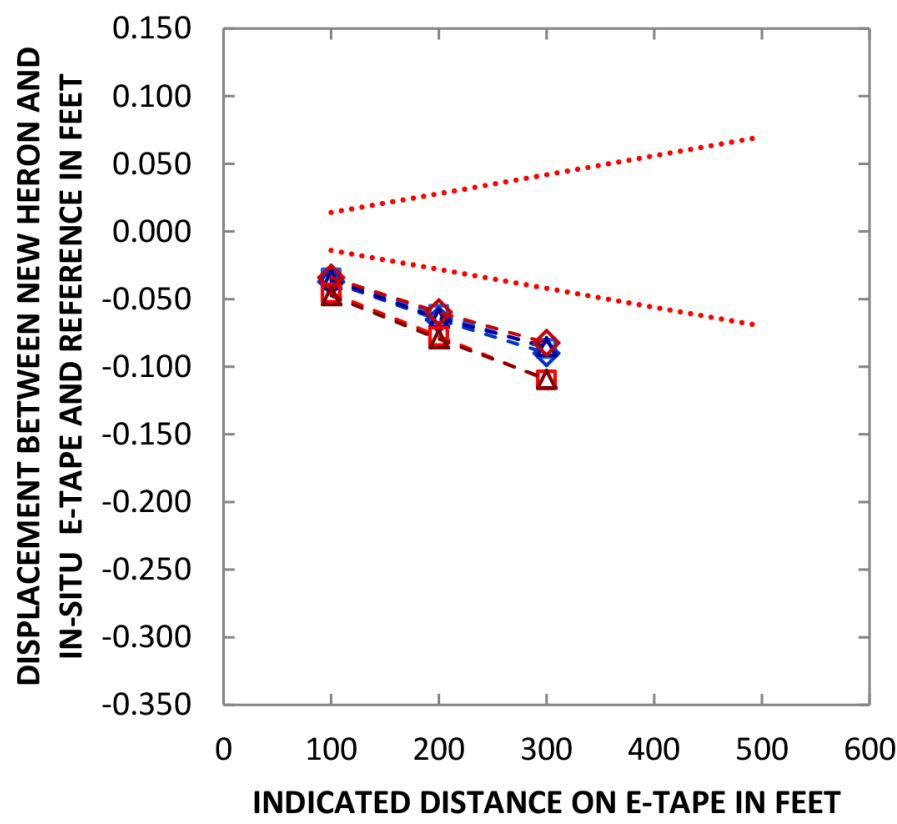

\section{EXPLANATION}

$--\square-$ New Heron \#1

$-\diamond-$ New Heron \#2

$--\Delta-$ New Heron \#3

$-\square-$ New In-Situ \#1

$-\diamond-$ New In-Situ \#2

$--\Delta-$ New In-Situ \#3

........ 0.01-ft accuracy

INDICATED DISTANCE ON E-TAPE IN FEET

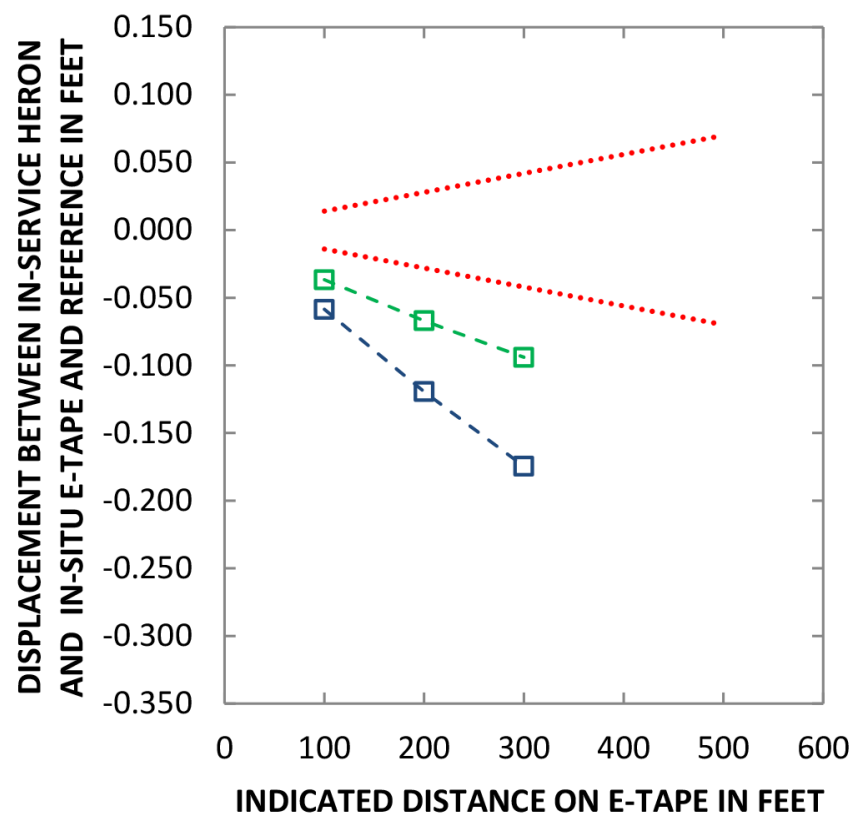

\section{EXPLANATION}

- $\square$ - In-service Heron \#1

- - - - In-service In-Situ \#1

0.01-ft accuracy

Figure 13. The cumulative measured displacement between Heron electric test tapes (E-TAPES) and the steel reference tape plotted with an expected accuracy of 0.01 foot (ft) per 100-ft length for new (top chart) and for Water Science Center in-service E-TAPES (bottom chart). The E-TAPES were tested with in-use tension. 


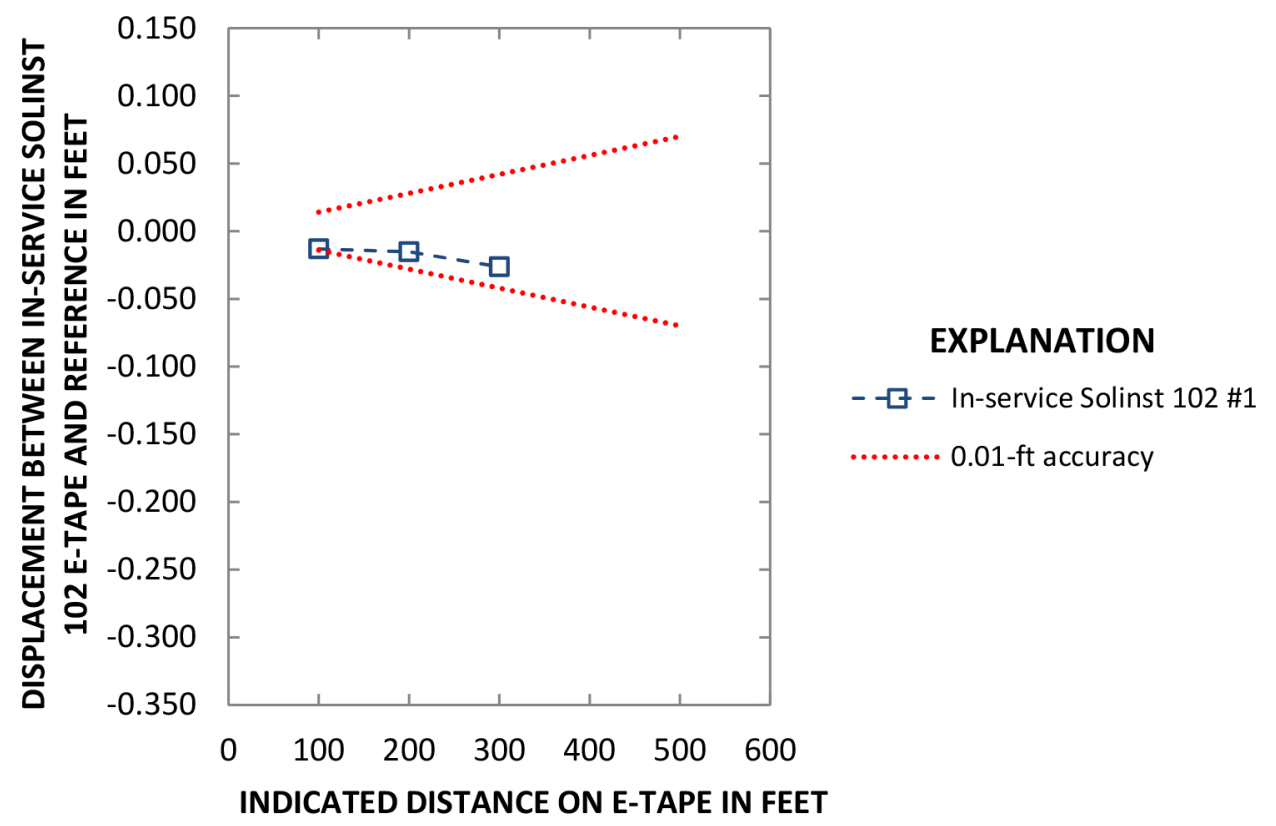

Figure 14. The cumulative measured displacement between in-service Solinst model 102 electric test tapes (E-TAPES) and the steel reference tape plotted with an expected accuracy of 0.01 foot (ft) per 100-ft length. The E-TAPES were tested with in-use tension.

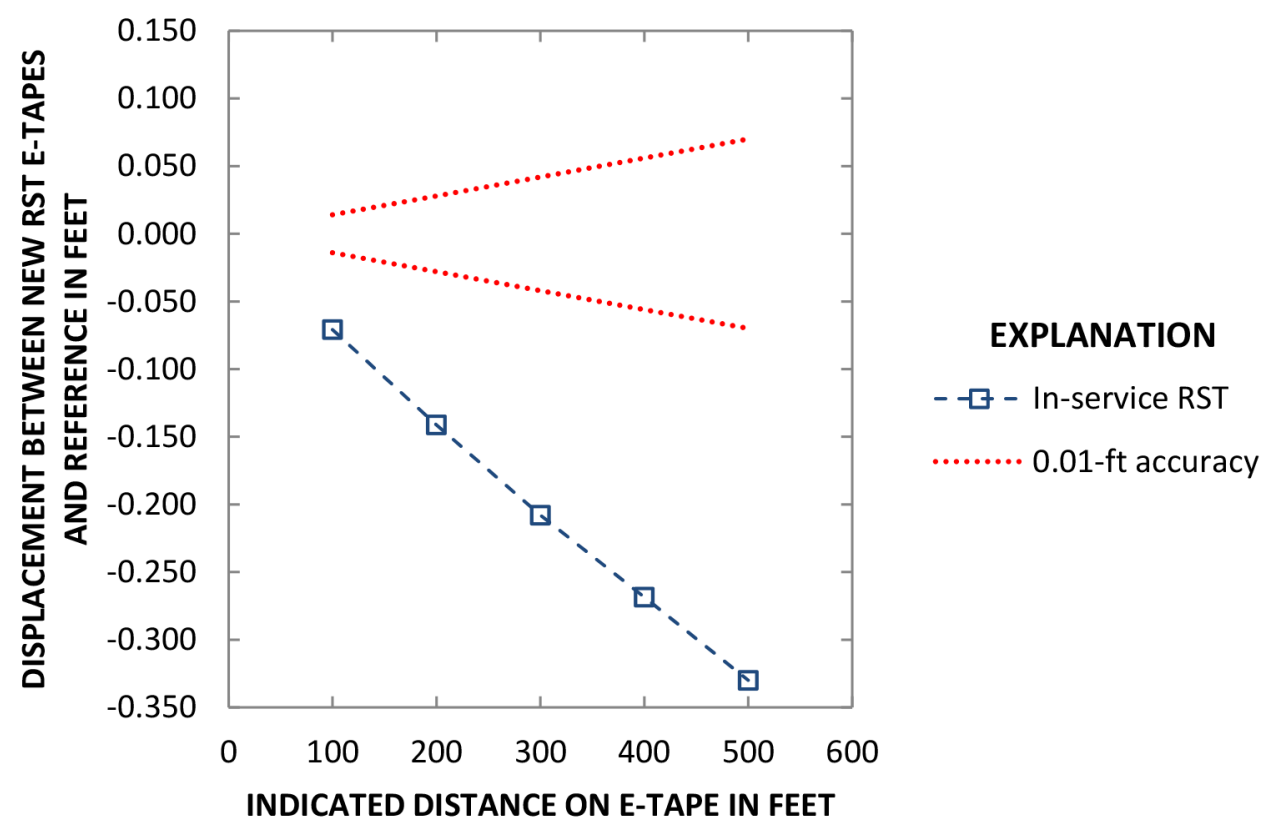

Figure 15. The cumulative measured displacement between in-service RST model 3001 electric test tapes (E-TAPES) and the steel reference tape plotted with an expected accuracy of 0.01 foot (ft) per 100-ft length. The E-TAPES were tested with in-use tension. 


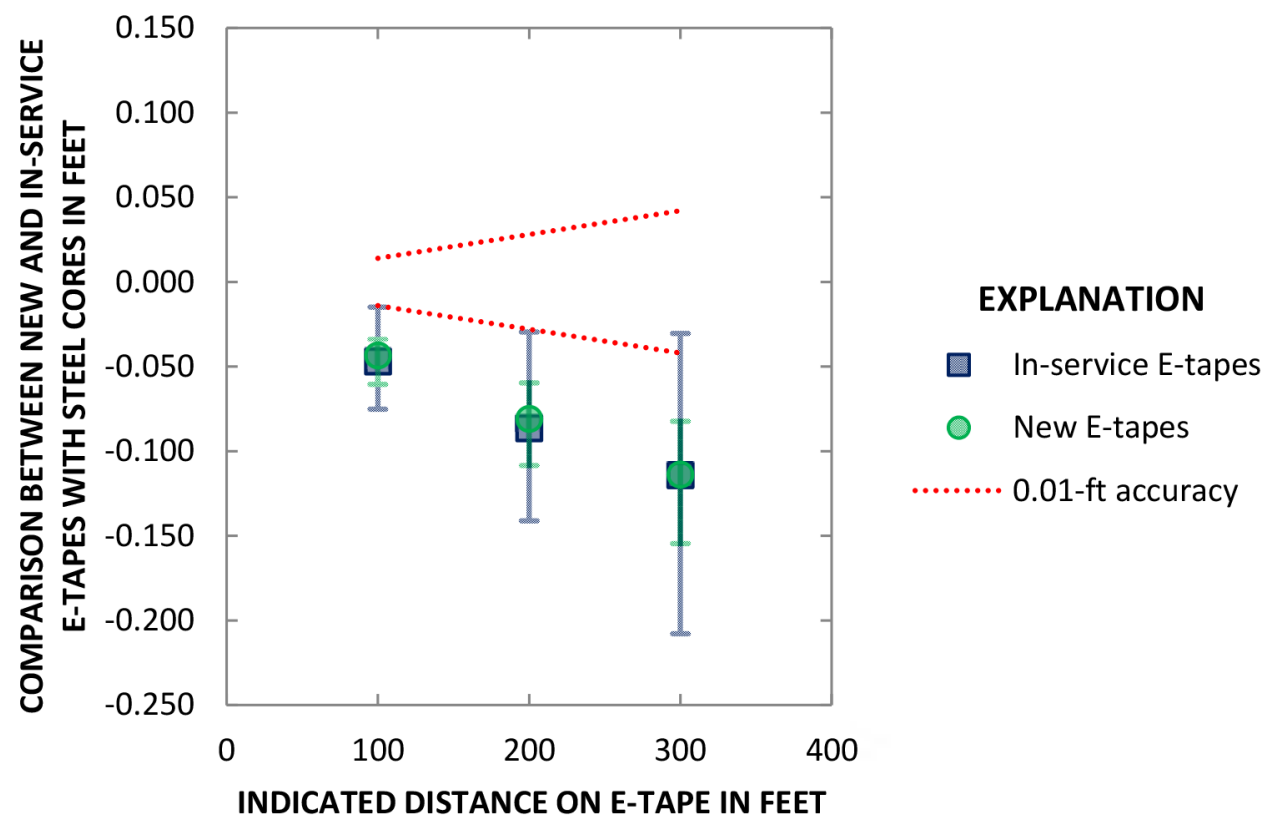

Figure 16. For new and in-service electric test tapes (E-TAPES) with steel tape cores, the cumulative measured displacement between E-TAPES and the steel reference tape plotted with an expected accuracy of 0.01 foot (ft) per 100-ft length. The E-TAPES were tested with in-use tension. Vertical error bars are the maximum and minimum displacement measured.

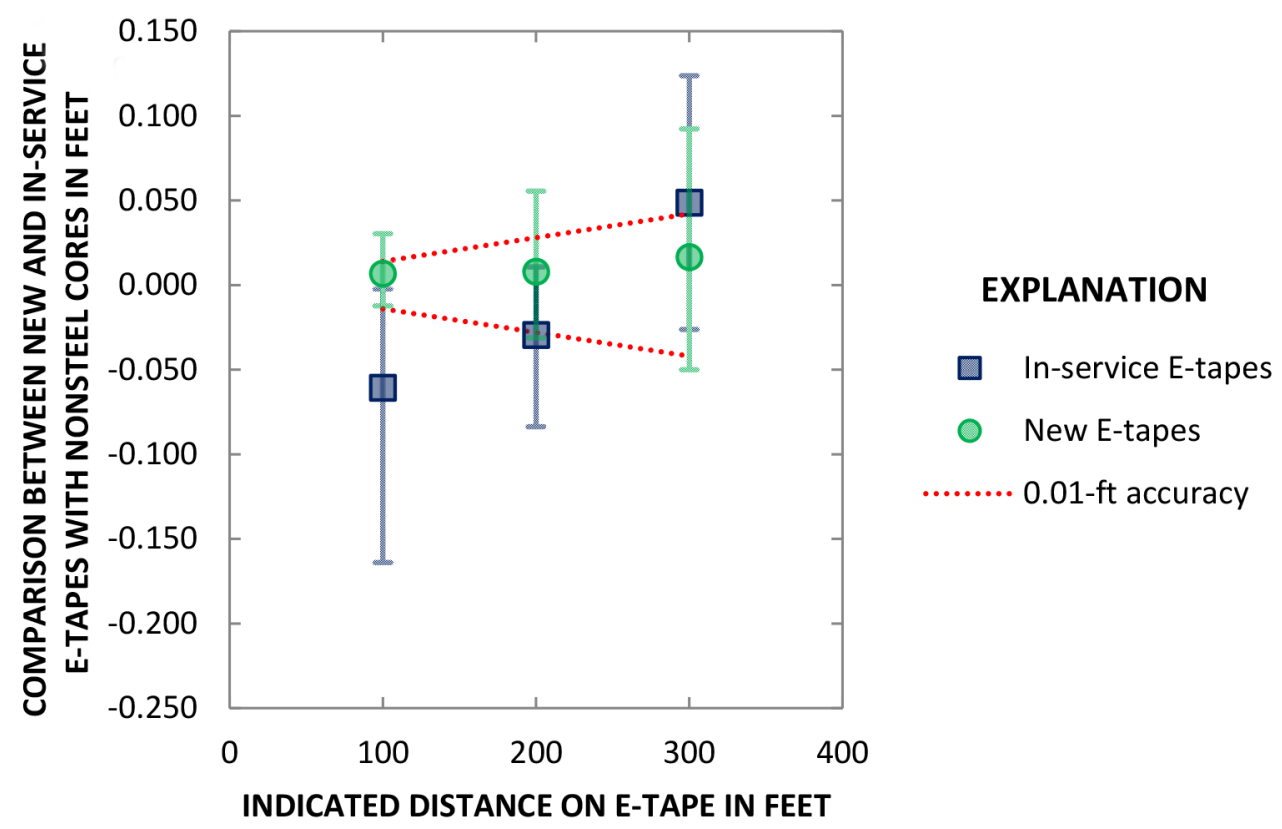

Figure 17. For new and in-service electric test tapes (E-TAPES) without steel tape cores, the cumulative measured displacement between E-TAPES and the steel reference tape plotted with an expected accuracy of 0.01 foot (ft) per 100- $\mathrm{ft}$ length. The E-TAPES were tested with in-use tension. Vertical error bars are the maximum and minimum displacement measured. 


\section{Comparison of In-Service Steel and Electric- Tape Results}

The in-service electric tapes showed more signs of wear than the in-service steel tapes (table 15). Almost all electric tapes had signs of wear. One electric tape did not detect water because of a broken wire in either the tape length or probe. The steel tapes, by comparison, were in good, legible condition. Some steel tapes had minor rust, were missing sections, and had kinks in a few intervals. These wear and tear issues were minor and did not affect the accuracy or use of the steel tapes.

Electric tapes were not as easy to calibrate as the steel tapes because the tension applied to the electric tapes is different than the tension applied to the reference steel tape and the friction from the electric-tape coatings makes the tapes harder to align and tension. Surface friction can cause the electric tape to stretch unevenly and contribute to measurement errors.

Figure 18 compares the displacements measured during calibrations for the in-service steel and electric tapes and shows that the range of electric-tape measurement variation can be much larger than the steel tapes. The in-service steel tape intervals measured within $0.01 \mathrm{ft}$ of the reference over the 100-ft interval. Any of the in-service steel tapes, when used properly, will give an accurate water-level measurement without a tape correction. None of the in-service electric tapes in the study sample will give a water-level measurement within $\pm 0.01 \mathrm{ft}$ per $100 \mathrm{ft}$ without a tape correction.

\section{EXPLANATION \\ In-service E-tapes \\ - In-service steel tapes \\ 0.01-ft accuracy}

Figure 18. For steel and in-service electric test tapes (E-TAPES), the cumulative measured displacement between in-service E-TAPES and the steel reference tape plotted with an expected accuracy of 0.01 foot $(\mathrm{ft}$ ) per 100 - $\mathrm{ft}$ length. The E-TAPES were tested with in-use tension. Vertical error bars are the maximum and minimum displacement measured.

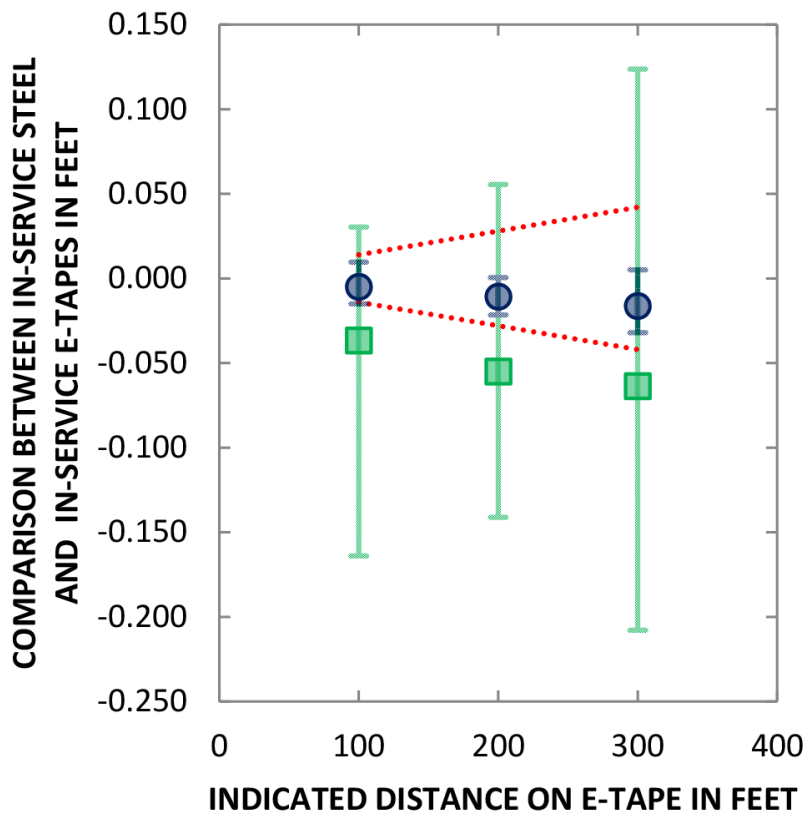

Table 15. New and in-service electric-tape calibration data. Displacement is the measured length difference between the electric tape and the steel reference tape. Positive displacements are for tapes that measure long, and negative displacements are for tapes that measure short.

$[\mathrm{ft}$, feet; w/o, without]

\begin{tabular}{|c|c|c|c|c|c|c|c|c|}
\hline \multirow[b]{3}{*}{ Tape models } & \multicolumn{4}{|c|}{ New tapes } & \multicolumn{4}{|c|}{ In-service tapes } \\
\hline & \multirow[b]{2}{*}{$\begin{array}{l}\text { Number } \\
\text { of tapes }\end{array}$} & \multirow[b]{2}{*}{$\begin{array}{c}\text { Number of } \\
\text { intervals }\end{array}$} & \multicolumn{2}{|c|}{ Displacement } & \multirow[b]{2}{*}{$\begin{array}{c}\text { Number of } \\
\text { tapes }\end{array}$} & \multirow[b]{2}{*}{$\begin{array}{l}\text { Number of } \\
\text { intervals }\end{array}$} & \multicolumn{2}{|c|}{ Displacement } \\
\hline & & & $\begin{array}{c}\text { Average } \\
\text { in } \mathrm{ft}\end{array}$ & $\begin{array}{c}\text { Standard } \\
\text { deviation } \\
\text { in } \mathrm{ft}\end{array}$ & & & $\begin{array}{c}\text { Average } \\
\text { in } \mathrm{ft}\end{array}$ & $\begin{array}{c}\text { Standard } \\
\text { deviation } \\
\text { in } \mathrm{ft}\end{array}$ \\
\hline $\begin{array}{l}\text { Durham Geo Slope } \\
\text { Indicator }\end{array}$ & 3 & 9 & -0.0010 & 0.0241 & 4 & 8 & -0.0252 & 0.0776 \\
\hline Solinst 101 & 3 & 9 & -0.0040 & 0.0143 & 5 & 24 & -0.0264 & 0.0349 \\
\hline Steel-core tapes & 9 & 36 & -0.0311 & 0.0061 & 3 & 7 & -0.0433 & 0.0161 \\
\hline Tapes w/o steel core & 6 & 27 & -0.0022 & 0.0195 & 11 & 35 & -0.0246 & 0.0475 \\
\hline
\end{tabular}




\section{Summary}

The accuracy of groundwater-level tapes was investigated by developing a calibration method and device, and testing the accuracy of a sample of in-service steel and electric groundwater-level measuring tapes. The recommended calibration method is a side-by-side tape comparison method based on a National Institute for Standards and Technology (NIST) standard operating procedure (NIST, 1986). The calibration method can be performed by U.S. Geological Survey Water Science Centers with readily available equipment. The procedure is applicable to all well tapes-steel and electric - and can accurately calibrate well tapes with a calibrated steel reference tape. A mechanical calibration device, composed of an anchor and tensioner, was also developed and can be used with the calibration procedure to enhance accuracy and repeatability. The estimated expanded measurement uncertainty for conducting the calibrations outdoors with the method and not using the CD2 device (CD2) is $0.005 \mathrm{ft}$. The estimated expanded measurement uncertainty for conducting calibrations indoors with the method and the CD2 is $0.001 \mathrm{ft}$. Replicated calibration testing of a steel tape indoors with the method and the CD2 had a standard uncertainty of $0.0011 \mathrm{ft}$ for an interval measurement from a single measurement; $0.0011 \mathrm{ft}$ for an interval measurement computed from four averaged, replicated measurements; and $0.0016 \mathrm{ft}$ for an interval measurement computed from two averaged, replicated measurements. Two testing-bias estimation methods gave test-bias estimates from $-0.007 \mathrm{ft}$ to $-0.004 \mathrm{ft}$ per $100-\mathrm{ft}$ interval and indicate that the calibration method is adequate for calibrating tapes to $\pm 0.01 \mathrm{ft}$, but could be improved.
The accuracy of a sample of 29 in-service steel and electric groundwater-level tapes was investigated using the calibration method and the CD2. The condition of the tapes was noted and the tapes were tested for compliance with the accuracy requirement of $\pm 0.01 \mathrm{ft}$ per $100 \mathrm{ft}$. The in-service steel tapes were all in good condition. In contrast, the electric tapes had signs of wear and were harder to read. All of the in-service steel tapes could be used as is, without tape corrections, to achieve an accuracy of $\pm 0.01 \mathrm{ft}$. The in-service electric tapes were accurate to about $\pm 0.03 \mathrm{ft}$ per $100 \mathrm{ft}$. All of the in-service electric tapes require tape corrections to achieve an accuracy of $\pm 0.01 \mathrm{ft}$ per $100 \mathrm{ft}$. A comparison of new with in-service electric tapes found that steel-core electric tapes maintained their length and accuracy better than electric tapes without a steel core.

\section{Acknowledgments}

The USGS Office of Ground Water (OGW) funded the development of the calibration method and device and the study of in-service groundwater tapes described in this report. The authors thank William Cunningham (Chief, USGS OGW) and Rodney Sheets (USGS Water Science Field Team) for their help, patience, and support for this study. The authors also thank Jim Jelinski (retired) whose ideas and technical support significantly contributed to the study and report contents. The following U.S. Geological Survey Water Science Centers are thanked for volunteering their groundwaterlevel tapes for the in-service tape study: Arizona, Arkansas, Nebraska, Nevada, New Jersey, North Carolina, Ohio, Pacific Islands, Pennsylvania, South Carolina, and Tennessee. 


\section{References Cited}

American Society of Mechanical Engineers, 2009, Performance standard for steel measuring tapes: American Society of Mechanical Engineers Standard B89.1.7, 22 p.

Brunett, J.O., Barber, N.L., Burns, A.W., Fogelman, R.P., Gillies, D.C., Lidwin, R.A., and Mack, T.J., 1997, A qualityassurance plan for district ground-water activities of the U.S. Geological Survey: U.S. Geological Survey Open-File Report 97-11, p. 12.

Cunningham, W.L., and Schalk, C.W., comps., 2011a, Groundwater technical procedures of the U.S. Geological Survey; GWPD 1-Measuring water levels by use of a graduated steel tape: U.S. Geological Survey Techniques and Methods, book 1, chap. A1, 4 p.

Cunningham, W.L., and Schalk, C.W., comps., 2011b, Groundwater technical procedures of the U.S. Geological Survey; GWPD 4-Measuring water levels by use of an electric tape: U.S. Geological Survey Techniques and Methods, book 1, chap. A1, 5 p.

Eberhardt, K.R., 1990, Wadsworth, H.M., ed., Surveying sampling methods: Handbook of statistical methods for engineers and scientists, Part 3.9: New York, McGraw-Hill, Inc., p. 15.

Garber, M.S., and Koopman, F.C., 1968, Methods of measuring water levels in deep wells: U.S. Geological Survey Techniques of Water-Resources Investigations, book 8, chap. A1, p 6 .
Holmes, R.R., Terrio, P.J., Harris, M.A., and Mills, P.C., 2001, Introduction to field methods for hydrologic and environmental studies, Chapter 4 Measuring and mapping groundwater levels in wells: U.S. Geological Survey Open-File Report 01-50, p. 195-197.

International Standards Organization, 1992, "Quality assurance requirements for measuring equipment-Part 1: Metrological confirmation system for measuring equipment," ISO 10012-1:1992: Geneva, Switzerland, International Organization for Standardization.

International Standards Organization (GUM),1993, "Guide to the Expression of Uncertainty in Measurement," ISBN 92-67-10188-9, BIPM, IEC, IFCC, ISO, IUPAC, IUPAP, OIML: Geneva, Switzerland, International Organization for Standardization.

Jelinski, James, Clayton, C.S., and Fulford, J.M., 2015, Accuracy testing of electric groundwater-level measurement tapes: U.S. Geological Survey Open-File Report 2014-1236, 27 p.

Moffitt, F.H., and Bouchard, H., 1975, Surveying (6th ed.): New York, Intext Educational Publishers, p. 32-35.

National Institute of Standards and Technology, 1986, Recommended standard operating procedure for calibration of steel tapes; Tape-to-tape method: Gaithersburg, Md., National Institute of Standards and Technology, Physical Measurement Laboratory, Standard Operating Procedure Number 12. 


\section{Appendix 1. Calibration Worksheet}

Version 2.6

HIF

Page 1 of 2

Well Tape Calibration Worksheet

General Information

\begin{tabular}{|l|l|}
\hline Date: & Brief Description of Test Location: \\
\hline WSC / Field Office Location: & \\
& Test Location Conditions: \\
\hline \multirow{3}{*}{ Test Personnel: } & \\
& Average Ambient Air Temp: \\
\cline { 2 - 2 } & Average Surface Temp: \\
\hline
\end{tabular}

Tape Information

\begin{tabular}{|l|l|}
\hline \multicolumn{1}{|c|}{ Calibration Reference Tape } & \multicolumn{1}{|c|}{ Tape to be Calibrated (Measurement Tape) } \\
\hline Type: (Steel or Electric) & Type: (Steel or Electric) \\
\hline Manufacturer: & Manufacturer: \\
\hline Model: & Model: \\
\hline Tape Owner: & Tape Owner: \\
\hline Tape ID: & Tape ID: \\
\hline Tape Length: & Tape Length: \\
\hline Calibration Correction: & First Length Mark on Tape: \\
\hline General Tape Condition: & General Tape Condition: \\
& \\
\hline
\end{tabular}

Test Information

\begin{tabular}{|l|l|}
\hline \multicolumn{1}{|c|}{ Calibration Pull Forces } & \multicolumn{1}{c|}{ Interval Information } \\
\hline Calibration Reference Tape: & Calibration Interval: \\
\hline Measurement Tape: & Number of Intervals: \\
\hline
\end{tabular}

\section{Test Data}

Measurement Resolution: (for example: $0.0005^{\prime}$ or $0.0025^{\prime}$ )

Tape Correction
\begin{tabular}{|l|l|l|}
\hline Length Interval & Interval Correction & Cumulative Correction \\
\hline & & \\
\hline & & \\
\hline & & \\
\hline & & \\
\hline & & \\
\hline & & \\
\hline & & \\
\hline & & \\
\hline & & \\
\hline For longer tapes, record additional offset values on back of sheet. & \\
\hline
\end{tabular}

\section{Uncertainty}

Calculated Uncertainty: 

Tape Measurement Difference per Interval (record the length interval and difference measurements, measurements should be to the indicated resolution)

\begin{tabular}{|l|l|l|l|}
\hline 1$)$ & $2)$ & $3)$ & $4)$ \\
\hline 5$)$ & $6)$ & $7)$ & 83 \\
\hline \multicolumn{2}{|l|}{ For longer tapes, record additional interval measurements on back of sheet. } \\
\hline
\end{tabular}

\begin{tabular}{|c|c|c|c|}
\hline $2^{\text {nd }}$ Measurements & & & Tapes in opposite positions \\
\hline \multicolumn{4}{|c|}{$\begin{array}{l}\text { Tape Measurement Difference per Interval (record the length interval and difference measurements, } \\
\text { measurements should be to the indicated resolution) }\end{array}$} \\
\hline 1) & 2) & 3) & \begin{tabular}{l|l|} 
& $4)$ \\
\end{tabular} \\
\hline 5) & 6) & 7) & 8) \\
\hline
\end{tabular}

\begin{tabular}{|c|c|c|c|}
\hline $3^{\text {rd }}$ Measurements & & & Tapes in initial positions \\
\hline \multicolumn{4}{|c|}{$\begin{array}{l}\text { Tape Measurement Difference per Interval (record the length interval and difference measurements, } \\
\text { measurements should be to the indicated resolution) }\end{array}$} \\
\hline 1) & 2) & 3) & \begin{tabular}{l|l|} 
& $4)$ \\
\end{tabular} \\
\hline 5) & 6) & 7) & 8) \\
\hline
\end{tabular}

\begin{tabular}{|c|c|c|c|}
\hline \multicolumn{3}{|l|}{$4^{\mathrm{t}}$ Measurements } & Tapes in opposite positions \\
\hline \multicolumn{4}{|c|}{$\begin{array}{l}\text { Tape Measurement Difference per Interval (record the length interval and difference measurements, } \\
\text { measurements should be to the indicated resolution) }\end{array}$} \\
\hline 1) & 2) & 3) & \begin{tabular}{l|l|} 
& $4)$ \\
\end{tabular} \\
\hline 5) & 6) & 7) & 8) \\
\hline
\end{tabular}

Electric Tape Information

\begin{tabular}{|ll|l|}
\hline In-Use Pull Forces (if used): & $\begin{array}{l}\text { Probe Correction Measurements: } \\
1^{\text {st }}\end{array}$ \\
\hline & - & $2^{\text {nd }}$ \\
\hline
\end{tabular}$\quad$\begin{tabular}{l}
$3^{\text {rd }}$ \\
\hline
\end{tabular}

Remarks 
For additional information, visit

http://water.usgs.gov/hif/

USGS Publishing Service Center staff: Marilyn A. Billone, Editor

Ronald S. Spencer, layout 

